Research Article

\title{
Experimental Investigation on Web Crippling Property of High-Strength Cold-Formed (HSCF) Rectangular Steel Tube
}

\author{
Xianglong Liu, ${ }^{1}$ Jicheng Zhang $\mathbb{D}^{1}{ }^{1}$ Yuanqi Li, ${ }^{2}$ Lei Zeng, ${ }^{1}$ and Guofeng Du ${ }^{1}$ \\ ${ }^{1}$ School of Urban Construction, Yangtze University, Jingzhou 434023, China \\ ${ }^{2}$ College of Civil Engineering, Tong Ji University, Shanghai 200092, China \\ Correspondence should be addressed to Jicheng Zhang; zhangjicheng@yangtzeu.edu.cn
}

Received 1 July 2020; Revised 13 September 2020; Accepted 16 October 2020; Published 29 October 2020

Academic Editor: Jiang Jin

Copyright ( 92020 Xianglong Liu et al. This is an open access article distributed under the Creative Commons Attribution License, which permits unrestricted use, distribution, and reproduction in any medium, provided the original work is properly cited.

To research the web crippling performance (i.e., the ultimate web crippling bearing capacity and ductility) of high-strength coldformed (HSCF) rectangular steel tubes under concentrated load, thirty-six specimens with different bearing plate width, width-toheight ratio, boundaries, and loading conditions are fabricated and tested in this paper. Particularly, four kinds of boundaries and loading conditions are utilized, including end-two-flange (ETF), end-one-flange (EOF), interior-two-flange (ITF), and interiorone-flange (IOF). Research revealed the failure modes of HSCF rectangular steel tubes under concentrated loads applied at the end or interior. Moreover, the load-displacement curves and load-strain curves are obtained. The results show that the ultimate crippling capacity of webs increases significantly with larger bearing plate width and width-to-height ratio. Specimens subjected to interior bearing load have higher ultimate strength and deformation capacity than counterparts that are subjected to bearing load at the end. Additionally, in the middle of the compression web, all strain measuring points enter the plasticity stage and finally appear in the plastic hinge area. Subsequently, the failure modes and ultimate bearing capacity are simulated by the finite element method (FEM), which is implemented via ABAQUS. By comparing the test results with the numerical values, demonstrate the effectiveness of the proposed numerical simulation on investigating the failure modes and the ultimate bearing capacity of HSCF rectangular steel tubes. Finally, regarding the conservative and dangerous calculation of web crippling ultimate bearing capacity in current codes, we can provide a good guidance for future work, particularly the proposed calculation equations for ultimate bearing capacity of HSCF rectangular steel tubes.

\section{Introduction}

The past decades have seen the rapid advances in structural engineering, and many new structural materials and configurations, such as cold-formed steel [1], high-strength steel (HHS) [2-4], concrete-filled steel tubes (CFSTs) [5-7], and fiber-reinforced polymer (FRP) structures [8-10], have been developed and applied to engineer practice. Among them, the cold-formed steel attracts much attention in civil engineering due to its efficient section form. During their service, cold-formed structures are subject to a variety of adverse effects that may result in damages, including overloading [11], corrosion [12-14], fatigue [15-17], and seismic excitation [18]. To find the common damage patterns of the cold-formed steel structures under different loading conditions, researchers have conducted many investigations on the web crippling properties of cold-formed thin-walled steel sections. According to the existing design rules [19-21], there are four stipulated loading conditions, including end-one-flange (EOF), interior-one-flange (IOF), end-two-flange (ETF), and interior-two-flange (ITF), which are classified via the position of the centralized loading on one or both flanges. The influence of cold-formed steel sections with web openings on the web crippling performance was studied by Uzzaman et al. [22,23], and the results showed that the first three factors affecting the web crippling strength were hole depth, bearing plate length, and web flat depth. Macdonald and Heiyantuduwa [24] carried out a comparative test on the web crippling performance of coldformed channel steel with and without constrained flange 
plate, and they provided formulas with better adaptability to calculate the web crippling strength. Zhou and Young $[25,26]$ demonstrated that the web crippling strength under the ETF loading increased faster than the counterpart with ITF loading when bearing length increased. Through experiments and finite element analyses, Zhou and Young [27] proposed reduction factor equations to characterize the web crippling strength of square hollow sections with a circular hole in the web. Based on tests of web crippling, Chen et al. [28] found that the ultimate bearing capacity of web crippling was inversely proportional to the slenderness ratio under loading conditions of EOF and ETF. The University of Hong Kong conducted a comprehensive laboratory test program involving 65 web failure tests of square and rectangular hollow sections of high-strength steel. The web failure tests were carried out under the loading conditions of EOF, IOF, ETF, and ITF, which are specified in the North American specification (NAS) [29] and the Australian/New Zealand standard (AS/NZS) [30]. The slenderness of the sample webs ranged from 8.3 to 35.8 webs. The test strength was compared with the current nominal strength predicted by NAS [29], AS/NZS [30], European specification (EC3) [31], and Australian standard AS4100 [32] to study the suitability of the existing code design provisions for web failure in cold bending high-strength steel tube sections. The reliability analysis was carried out to evaluate the reliability of the prepared web crippling design clauses.

So far, many researchers have conducted numerous experiments on the compressive strength or ultimate bearing capacity of the webs of cold-formed steel and high-strength steel. At the same time, the HSCF thin-walled steel is fabricated by bending ultrathin high-strength steel plates during a higher molding process; therefore, the high strength cold-formed (HSCF) thin-walled steel can save about $30 \%$ of the material, compared to the traditional coldformed thin-walled steel (such as Q235 and Q345). Now, high-strength cold-formed steel was widely used in practical projects, and it has different mechanical properties and failure modes due to high strength, thin thickness, poor ductility, and other properties. Generally, HSCF thin-walled steel suffers local crippling before global buckling; thus, it is necessary to study its local crippling behavior. For instance, Li and Young [33] conducted the web crippling tests of HSCF steel rectangular hollow sections under load conditions at the end and interior, and they also verified the effectiveness of the proposed finite element model (FEM) by comparing the experimental results with the numerical values. Meanwhile, the web crippling of HSCF steel tubes under other loading conditions has been studied [34, 35], and it is found that the existing codes are not very practical since there is an obvious difference between measured strength and the nominal strength stipulated via codes. Thus, based on the experimental and numerical results, they evaluated and improved the existing codes about web crippling. In addition, four-point bending tests on HSCF steel tubular beams were conducted by Ma et al. [36], and they demonstrated that the effective rotation capacities of the sections were reduced due to the low ductility of the material. And through the method of the comparison, it showed that, $t$, the current codes of practice are mostly conservative for the design of HSCF tubes subjected to uniform bending moment, but no suitable formula for calculating ultimate bearing capacity was proposed. Some web crippling tests of HSCF channels were implemented by Young and Hancock [37], and the results indicated that the web crippling strength was more than half of the predicted value under IOF or ETF loading conditions. Zhou and Young [38] studied the web crippling of HSCF stainless steel at high temperatures via FEM, and the numerical results showed that the numerical analyses could predict the behavior of web crippling. Compared to existing experimental studies, the web damage characteristics of HSCF steel under four loading conditions (EOF, IOF, ETF, and ITF) are systematically studied in this paper.

In this paper, the web crippling performance of HSCF rectangular steel tubes under concentrated load was studied. The stress and strain distribution at the web area and the total displacement of the loading end were measured. The deformation and failure of HSCF rectangular steel tubes under concentrated load were observed and analyzed, and their ultimate bearing capacity was recorded. Numerical simulations were performed, and their effectiveness was verified via experiments. Finally, the calculation equations for the ultimate bearing capacity of HSCF rectangular steel tubes were proposed, which could provide a good guidance for future work.

\section{Experimental Investigation}

2.1. Test Specimens. In order to research the web crippling properties of HSCF steel tubes, thirty-six such tubes with different boundary and loading conditions were tested in this paper. The wall thickness of all specimens is $5 \mathrm{~mm}$. The schematic of rectangular steel tubular sections is depicted in Figure 1, where $h$ denotes the nominal height (from 100 to $200 \mathrm{~mm}$ ) and $r$ denotes the pipe corner radii. Different specimens have different pipe corner radii, and $L$ represents the length (from 500 to $800 \mathrm{~mm}$ ). The bearing plates are fabricated by Q235 steel with thickness of $30 \mathrm{~mm}$ and length of $300 \mathrm{~mm}$. The width of bearing plate ranges from 50 to $150 \mathrm{~mm}$. The main function of the bearing plate is to ensure that concentrated load is applied locally to the specimen.

As mentioned above, specimens are tested under four loading conditions, i.e., EOF, IOF, ETF, and ITF. To eliminate the influence of boundary conditions, the distance from the edge of the bearing plate to the end of the specimen was set to the value that is more than 1.5 times the total height of the web. Figure 2 is a schematic of web crippling tests under four boundary and loading conditions, and photos of webs under four boundary and loading conditions are shown in Figure 3.

2.2. Specimen Labeling. In Table 1, the specimens were labeled to easily identify the boundary and loading condition, the nominal dimension of the specimen, the width of the bearing plate, and web crippling ultimate capacity of HSCF rectangular steel tubes (Pcr). For example, the label 


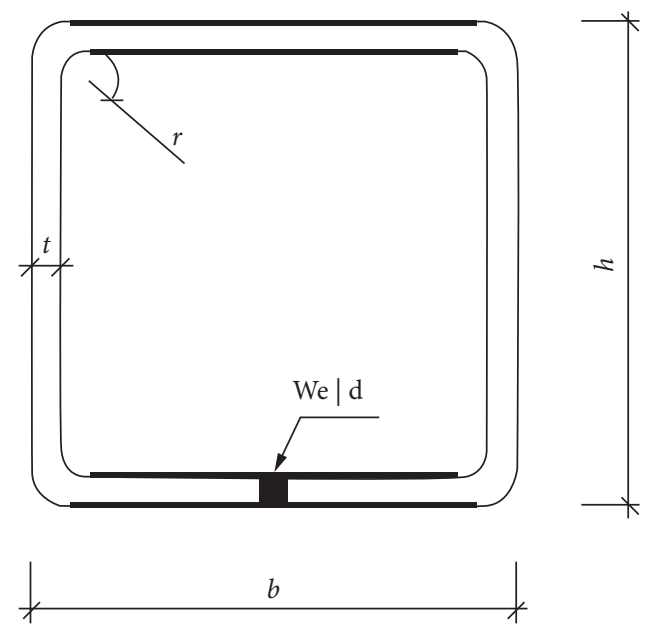

FIGURE 1: Definition of section symbol of rectangular steel tube.

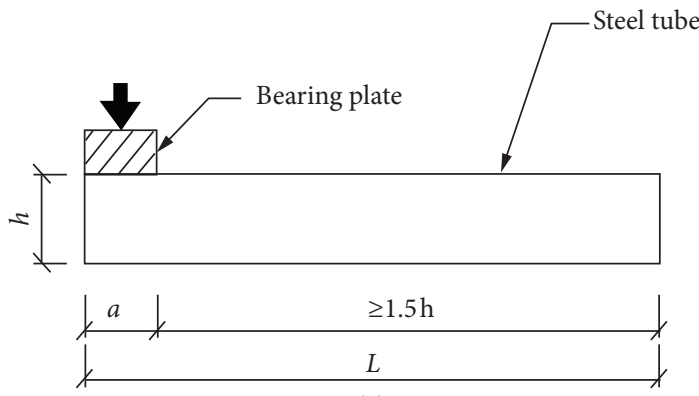

(a)

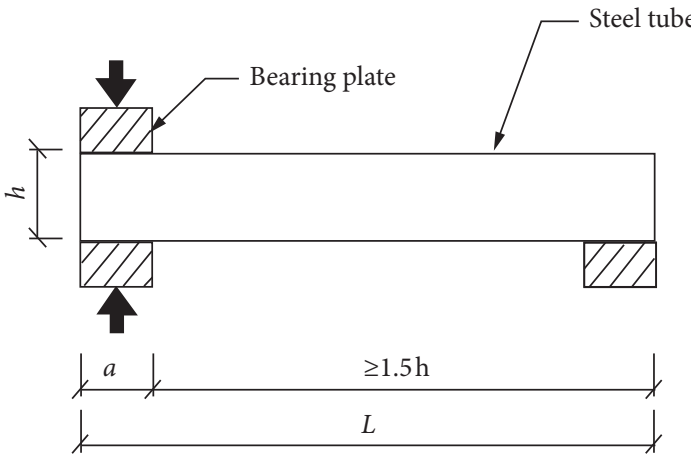

(c)

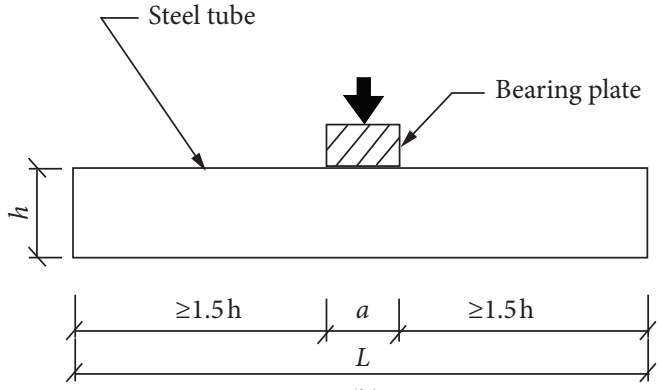

(b)

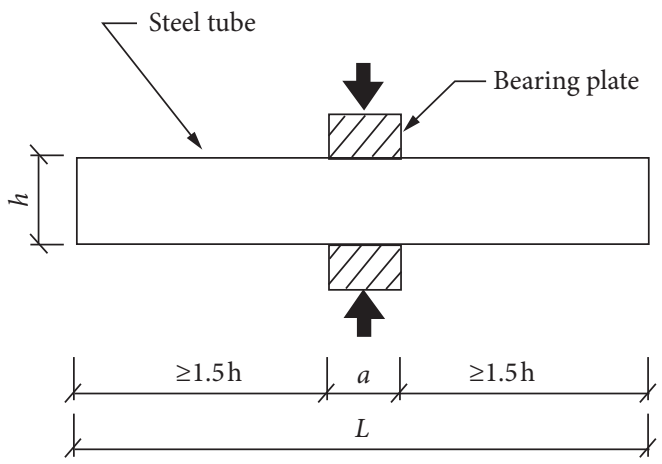

(d)

Figure 2: Schematic of web crippling tests in four boundary and loading conditions.

"RE100 $\times 500-\mathrm{EOF}-\mathrm{B} 50$ " defines the following highstrength cold-formed rectangular steel tubes: (1) the first letter "RE" denotes high-strength cold-formed steel section shape; (2) the $100 \times 500$ is the nominal dimension of the specimens in $\mathrm{mm}$, where 100 is the web height $(h)$, and 500 is the rectangular steel tubular length $(L)$; and (3) the label "B50" denotes the width of the bearing plate in $\mathrm{mm}$.

2.3. Material Properties. The material properties of steel used in this paper were determined by standard tensile tests. Three standard specimens used for tensile testing were sampled from the surface of each HSCF rectangular steel tube. The nominal coupons were prepared and tested according to Chinese Metallic Materials-Tensile testing at ambient temperature (GB/T228-2002) [39]. After processing, we use the grinding wheel to Polish the nonsmooth parts of the standard sample. The results of previous studies have shown that the surface state of the measured standard specimen has undergone some changes, and the effect on tensile strength is less than $5 \%$. The values of the tensile yield stress, ultimate tensile stress, elongation after fracture, and elastic modulus measured via the tests are presented in Table 2.

2.4. Loading and Test Program. In this test, the ultimate bearing capacities of the specimens were calculated 


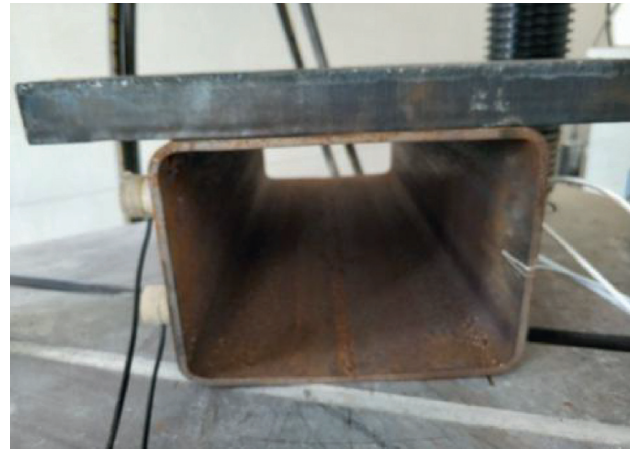

(a)

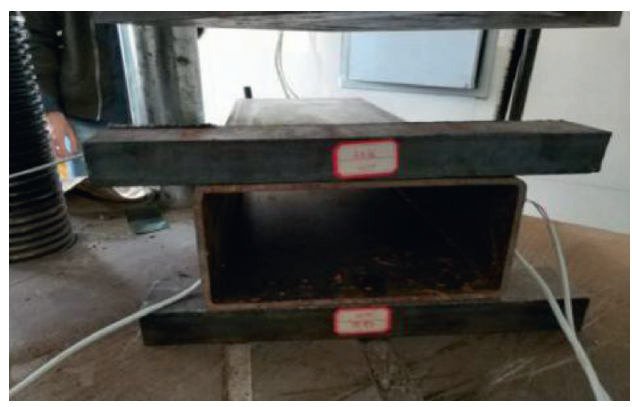

(c)

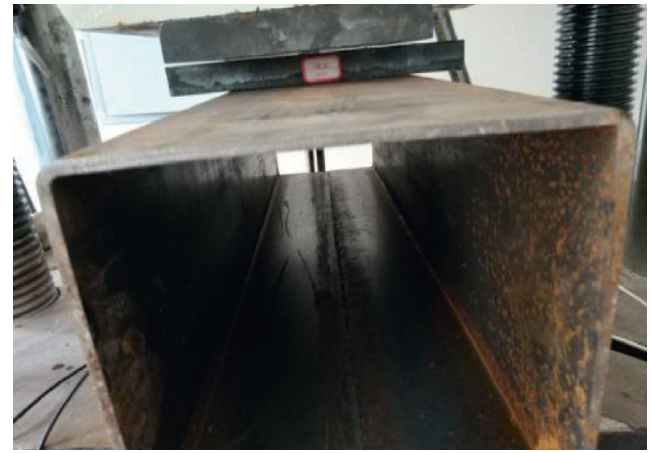

(b)

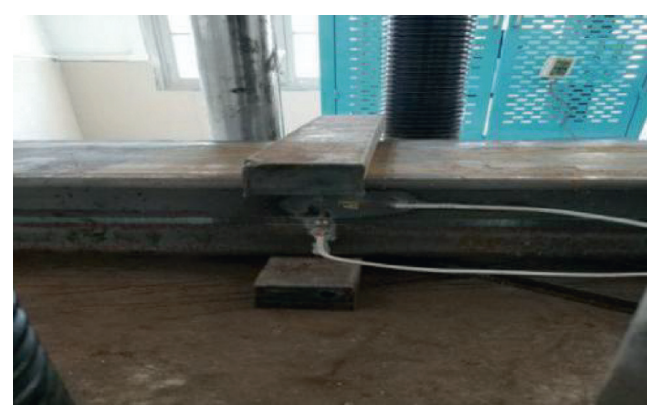

(d)

Figure 3: Photos of web crippling tests under four boundary and loading conditions. (a) EOF. (b) IOF. (c) ETF. (d) ITF.

according to the European steel structures' design code as the predicted load. Then, based on the predicted load, the load procedure was designed as follows: the preload accounted for $10 \%$ of the predicted load and was loaded slowly; in the formal loading stage, $20 \%$ of the predicted load was employed for continuous loading as the first stage. When the strain entered plasticity or displacement gauges increased rapidly (i.e., the strains and displacement were monitored), the load was applied continuously and slowly until failure appeared. In practice, the upper limit of hierarchical loading is adjusted according to displacement feedback.

Three strain gauge rosettes (S1-S3) were distributed with the same interval on the web of high-strength cold-formed rectangular steel tube, as shown in Figure 4. A right angle strain flower is arranged in the upper, middle, and lower part of the web corresponding to the center line of the supporting plate.

\section{Test Results}

3.1. Failure Modes. The failure modes of the HSCF rectangular steel specimen (tubular section) damaged by the web were out-of-plane buckling of the webs. Obvious plastic hinge area appeared in the middle of the webs. Under IOF boundary and loading conditions, one loading flange was concaved. Under ITF, EOF, and ETF boundary and loading conditions, two flanges were concaved, as shown in Figure 5.

3.2. Load-Displacement Curves. The load $(F)$ and vertical displacement $(\Delta)$ curves of the specimens under different loading conditions are depicted in Figures 6 and 7. The variation parameters of Figures 6 and 7 are the widths of the bearing plate and width-to-height ratio, respectively.

It can be seen from Figures 6 and 7 that the load-displacement curves of all specimens have basically the same trend. During the whole loading process, the deformation of the specimen can be divided into three stages: elasticity, buckling, and failure. The yield of steel is a gradual process, and there is no obvious yield point in the load-displacement curve. At the failure stage, the bearing capacity does not drop vertically, indicating that the ductility of the component is good. According to Figure 6, we can find that the ultimate bearing capacity increases with the increase of the width of the bearing plate under the condition of the same lengthwidth ratio of section and loading conditions. In addition, it can be seen that the specimens subjected to interior bearing load have higher ultimate strength and deformation capacity. Based on Figure 7, we can find that the ultimate bearing capacity increases with the increase of length-width ratio of section under the condition of the same bearing plate width and loading conditions. Meanwhile, it can be seen that specimens subjected to interior bearing load have higher ultimate strength and deformation capacity.

3.3. Load-Strain Curves. The strain gauge used in this paper is resistance strain gauge. Data were collected through the collection box of DH3816 static strain test system, and the actual collected strain data of the collection box requires calibration. It is found that the actual strain value should be divided by 200 . The load $(F)$ and strain $(\varepsilon)$ curves of the specimens under different loading conditions are shown in Figure 8 under the different bearing plates with width of $50 \mathrm{~mm}, 100 \mathrm{~mm}$, and $150 \mathrm{~mm}$, respectively. The load $(F)$ and 
TABLe 1: Parameter sand ultimate capacity of rectangular steel tubular sections under web crippling.

\begin{tabular}{|c|c|c|c|c|c|c|c|c|}
\hline Boundary and loading condition & Specimen & $b(\mathrm{~mm})$ & $h(\mathrm{~mm})$ & $L(\mathrm{~mm})$ & $a(\mathrm{~mm})$ & $t(\mathrm{~mm})$ & $b / h$ & $P_{\text {cr }}(\mathrm{kN})$ \\
\hline \multirow{9}{*}{ EOF } & $\mathrm{RE} 100 \times 500-\mathrm{EOF}-\mathrm{B} 50$ & 200 & 100 & 500 & 50 & 5 & 2 & 165.1 \\
\hline & $\mathrm{RE} 100 \times 500-\mathrm{EOF}-\mathrm{B} 100$ & 200 & 100 & 500 & 100 & 5 & 2 & 249.4 \\
\hline & $\mathrm{RE} 100 \times 500-\mathrm{EOF}-\mathrm{B} 150$ & 200 & 100 & 500 & 150 & 5 & 2 & 330.0 \\
\hline & $\mathrm{RE} 150 \times 500-\mathrm{EOF}-\mathrm{B} 50$ & 200 & 150 & 500 & 50 & 5 & 1.3 & 102.2 \\
\hline & $\mathrm{RE} 150 \times 500-\mathrm{EOF}-\mathrm{B} 100$ & 200 & 150 & 500 & 100 & 5 & 1.3 & 137.5 \\
\hline & $\mathrm{RE} 150 \times 500-\mathrm{EOF}-\mathrm{B} 150$ & 200 & 150 & 500 & 150 & 5 & 1.3 & 173.8 \\
\hline & $\mathrm{RE} 200 \times 500-\mathrm{EOF}-\mathrm{B} 50$ & 200 & 200 & 500 & 50 & 5 & 1 & 127.8 \\
\hline & $\mathrm{RE} 200 \times 500-\mathrm{EOF}-\mathrm{B} 100$ & 200 & 200 & 500 & 100 & 5 & 1 & 152.8 \\
\hline & $\mathrm{RE} 200 \times 500-\mathrm{EOF}-\mathrm{B} 150$ & 200 & 200 & 500 & 150 & 5 & 1 & 209.8 \\
\hline \multirow{9}{*}{$\mathrm{IOF}$} & RE100 × 800 - IOF - B50 & 200 & 100 & 800 & 50 & 5 & 2 & 254.9 \\
\hline & $\mathrm{RE} 100 \times 800-\mathrm{IOF}-\mathrm{B} 100$ & 200 & 100 & 800 & 100 & 5 & 2 & 324.7 \\
\hline & $\mathrm{RE} 100 \times 800-\mathrm{IOF}-\mathrm{B} 150$ & 200 & 100 & 800 & 150 & 5 & 2 & 399.0 \\
\hline & $\mathrm{RE} 150 \times 800-\mathrm{IOF}-\mathrm{B} 50$ & 200 & 150 & 800 & 50 & 5 & 1.3 & 281.6 \\
\hline & $\mathrm{RE} 150 \times 800-\mathrm{IOF}-\mathrm{B} 100$ & 200 & 150 & 800 & 100 & 5 & 1.3 & 379.0 \\
\hline & $\mathrm{RE} 150 \times 800-\mathrm{IOF}-\mathrm{B} 150$ & 200 & 150 & 800 & 150 & 5 & 1.3 & 472.4 \\
\hline & $\mathrm{RE} 200 \times 800-\mathrm{IOF}-\mathrm{B} 50$ & 200 & 200 & 800 & 50 & 5 & 1 & 243.7 \\
\hline & RE2 $200 \times 800-$ IOF - B100 & 200 & 200 & 800 & 100 & 5 & 1 & 261.8 \\
\hline & $\mathrm{RE} 200 \times 800-\mathrm{IOF}-\mathrm{B} 150$ & 200 & 200 & 800 & 150 & 5 & 1 & 291.0 \\
\hline \multirow{9}{*}{ ETF } & $\mathrm{RE} 100 \times 500-\mathrm{ETF}-\mathrm{B} 50$ & 200 & 100 & 500 & 50 & 5 & 2 & 157.8 \\
\hline & $\mathrm{RE} 100 \times 500-\mathrm{ETF}-\mathrm{B} 100$ & 200 & 100 & 500 & 100 & 5 & 2 & 248.8 \\
\hline & $\mathrm{RE} 100 \times 500-\mathrm{ETF}-\mathrm{B} 150$ & 200 & 100 & 500 & 150 & 5 & 2 & 342.0 \\
\hline & $\mathrm{RE} 150 \times 500-\mathrm{ETF}-\mathrm{B} 50$ & 200 & 150 & 500 & 50 & 5 & 1.3 & 99.0 \\
\hline & $\mathrm{RE} 150 \times 500-\mathrm{ETF}-\mathrm{B} 100$ & 200 & 150 & 500 & 100 & 5 & 1.3 & 131.2 \\
\hline & $\mathrm{RE} 150 \times 500-\mathrm{ETF}-\mathrm{B} 150$ & 200 & 150 & 500 & 150 & 5 & 1.3 & 167.0 \\
\hline & RE200 ×500 - ETF - B50 & 200 & 200 & 500 & 50 & 5 & 1 & 129.3 \\
\hline & $\mathrm{RE} 200 \times 500-\mathrm{ETF}-\mathrm{B} 100$ & 200 & 200 & 500 & 100 & 5 & 1 & 165.3 \\
\hline & $\mathrm{RE} 200 \times 500-\mathrm{ETF}-\mathrm{B} 150$ & 200 & 200 & 500 & 150 & 5 & 1 & 213.2 \\
\hline \multirow{9}{*}{ ITF } & RE100 × 800 - ITF - B50 & 200 & 100 & 800 & 50 & 5 & 2 & 267.9 \\
\hline & $\mathrm{RE} 100 \times 800-\mathrm{ITF}-\mathrm{B} 100$ & 200 & 100 & 800 & 100 & 5 & 2 & 329.0 \\
\hline & $\mathrm{RE} 100 \times 800-\mathrm{ITF}-\mathrm{B} 150$ & 200 & 100 & 800 & 150 & 5 & 2 & 417.0 \\
\hline & RE150 × $800-$ ITF - B50 & 200 & 150 & 800 & 50 & 5 & 1.3 & 230.6 \\
\hline & $\mathrm{RE} 150 \times 800-\mathrm{ITF}-\mathrm{B} 100$ & 200 & 150 & 800 & 100 & 5 & 1.3 & 231.1 \\
\hline & $\mathrm{RE} 150 \times 800-\mathrm{ITF}-\mathrm{B} 150$ & 200 & 150 & 800 & 150 & 5 & 1.3 & 270.9 \\
\hline & RE200 × $800-$ ITF - B50 & 200 & 200 & 800 & 50 & 5 & 1 & 278.0 \\
\hline & $\mathrm{RE} 200 \times 800-\mathrm{ITF}-\mathrm{B} 100$ & 200 & 200 & 800 & 100 & 5 & 1 & 232.5 \\
\hline & $\mathrm{RE} 200 \times 800-\mathrm{ITF}-\mathrm{B} 150$ & 200 & 200 & 800 & 150 & 5 & 1 & 359.0 \\
\hline
\end{tabular}

TABLE 2: Result of material characteristic test.

\begin{tabular}{lcccc}
\hline Member & $\sigma_{y}(\mathrm{MPa})$ & $\sigma_{u}(\mathrm{MPa})$ & $E\left(10^{5} \mathrm{MPa}\right)$ & $\varepsilon_{f}(\%)$ \\
\hline$\square 200 \times 100$ & 432 & 583 & 1.94 & 30 \\
$\square 200 \times 150$ & 468 & 629 & 2.01 & 31 \\
$\square 200 \times 200$ & 481 & 627 & 1.89 & 33 \\
\hline
\end{tabular}

strain $(\varepsilon)$ curves of the specimens with different length-width ratios of section are shown in Figure 9. The section lengthwidth ratios of specimen are 2, 1.3, and 1, respectively. The distribution of strain measuring points is shown in Figure 4. The results show that the strain measuring point $\mathrm{S} 2$ in the middle of the compression web under four boundary and loading conditions all enter into plasticity. Except for the test point S1 on the upper side of the web under the loading condition of the inner flange, the other test points on the upper and lower parts did not enter the plasticity.
Based on results in Figures 8 and 9, when the steel tubes are in the elastic stage, the strain of the specimens increases linearly with the increase of load. When the steel tubes enter the elastic-plastic stage and the plastic stage, the strain value suddenly increases, and the specimens begin to buckle. The change of strain reflects that the change of specimens is consistent with the test phenomena.

The ultimate bearing capacity and the deformation capacity of the specimen increase with larger width of the bearing plate, as depicted in Figure 8. Moreover, we can see from Figure 9 that the ultimate bearing capacity of specimens with the length-width ratio of 2 is the highest, followed by specimens with the length-width ratio of 1.33 , and the ultimate bearing capacity of specimens with the lengthwidth ratio of 1 is the lowest. This indicates that the ratio of width to height is proportional to the ultimate bearing capacity. After entering the plastic stage, the specimens with smaller width-to-height ratio have lower ductility. Since the 


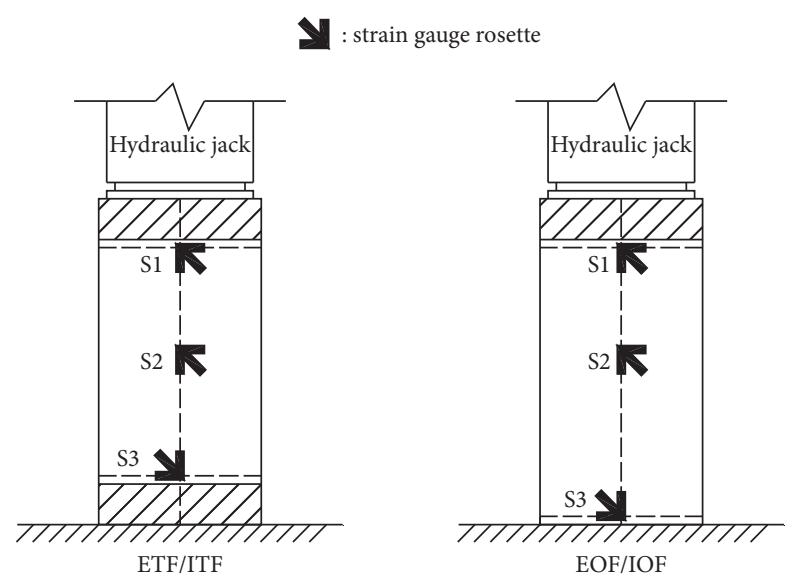

Figure 4: Arrangement of strain gauge rosettes.

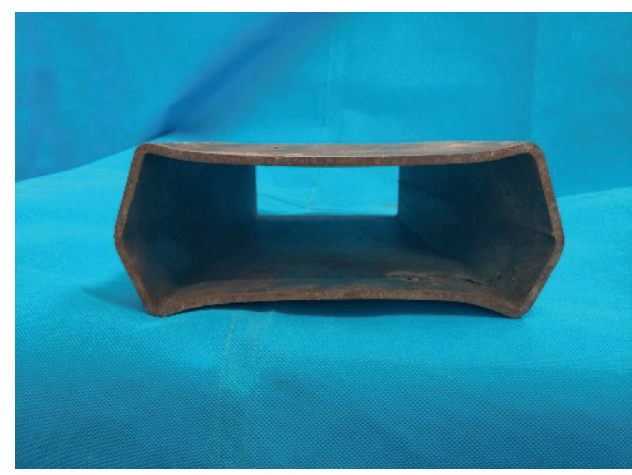

(a)

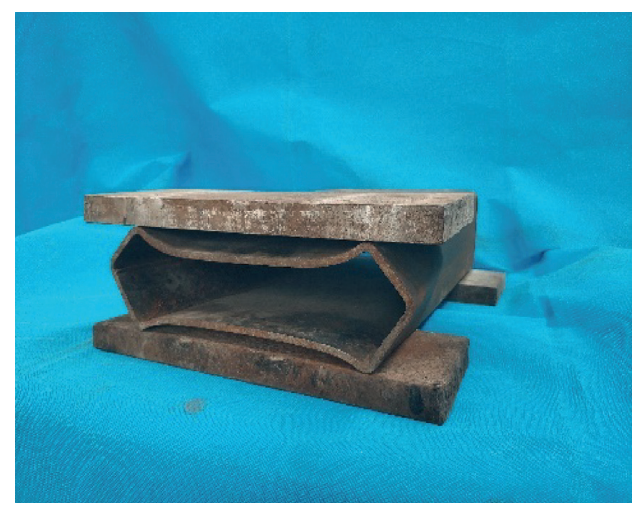

(c)

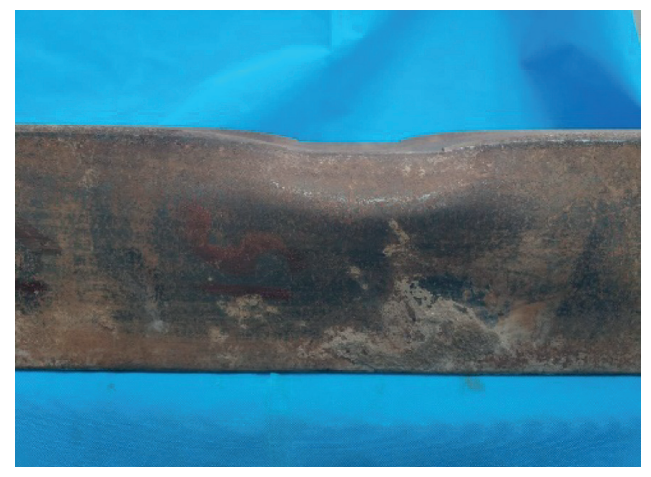

(b)

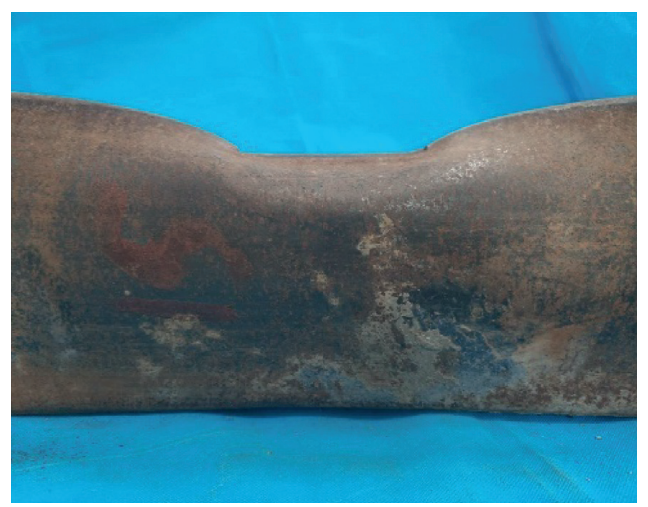

(d)

FIgure 5: Photos of failure modes under four boundary and loading conditions. (a) EOF. (b) IOF. (c) ETF. (d) ITF.

bearing capacity of the specimen with a small bearing plate width is low, the strain of the specimen with a small bearing plate width is large under the same load.

\section{Finite Element Models}

Currently, many kinds of finite element software have been developed and put into use, and ABAQUS is a powerful and widely used engineering simulation software, ranging from solving linear analysis problems to analyzing complex nonlinear problems. As a widely used simulation tool, it can not only solve a large number of structural stress-displacement problems but also address other engineering fields. Many studies have used ABAQUS to simulate HSCF components, for instance, based on the program developed by the finite strip method, Pham et al. [40] studied the shear buckling of three kinds of cold-formed thin-wall section steel with different shapes of web stiffening rib groove. By comparing the stress curves and buckling modes of the rectangular with triangular stiffeners, it is found that the shear capacity of the cold-curved thin-walled section steel with the rectangular stiffeners is the most obvious. Ren et al. 


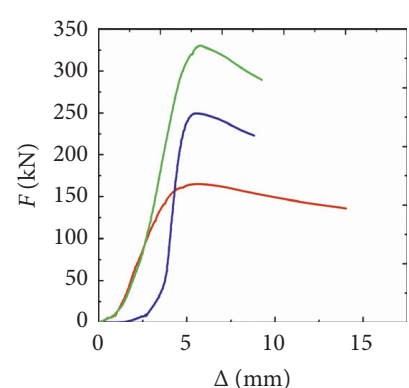

- RE100 $\times 500-\mathrm{EOF}-\mathrm{B} 50$

- RE100 $\times 500-\mathrm{EOF}-\mathrm{B} 100$

RE100 $\times 500-\mathrm{EOF}-\mathrm{B} 150$

(a)

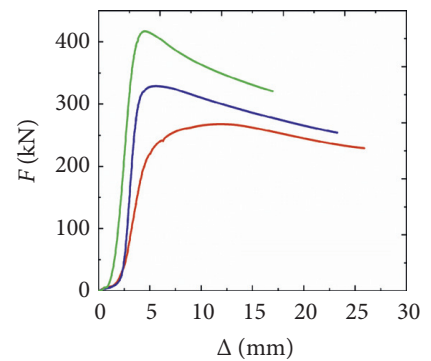

- RE100 $\times 800-$ ITF - B50

RE100 $\times 800-$ ITF - B 100

RE100 $\times 800-$ ITF - B150

(d)

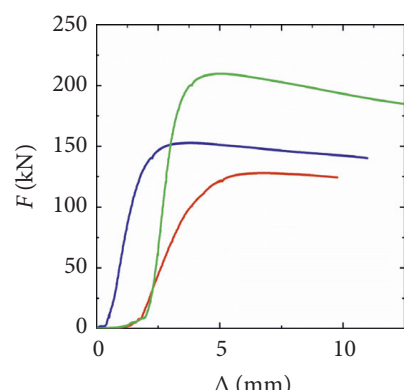

RE200 $\times 500-\mathrm{EOF}-\mathrm{B} 50$

RE200 $\times 500-E O F-B 100$

RE2 $200 \times 500-$ EOF - B150

(g)
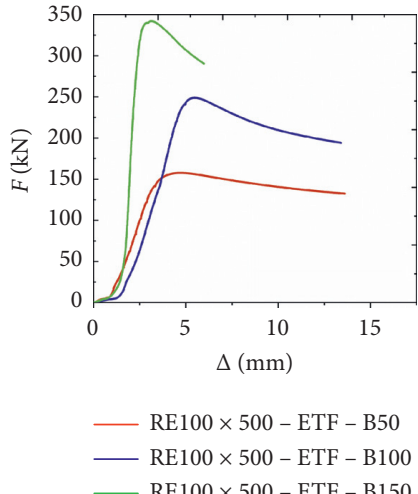

(b)

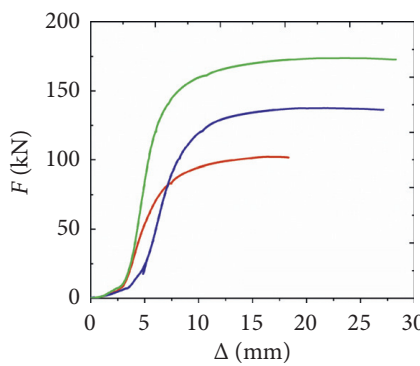

- RE150 $\times 500-\mathrm{EOF}-\mathrm{B} 50$

$\mathrm{RE} 150 \times 500-\mathrm{EOF}-\mathrm{B} 100$

RE150 × 500 - EOF - B150

(e)
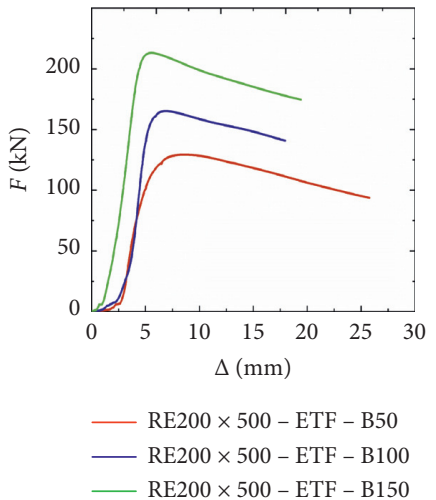

(h)

Figure 6: Continued.
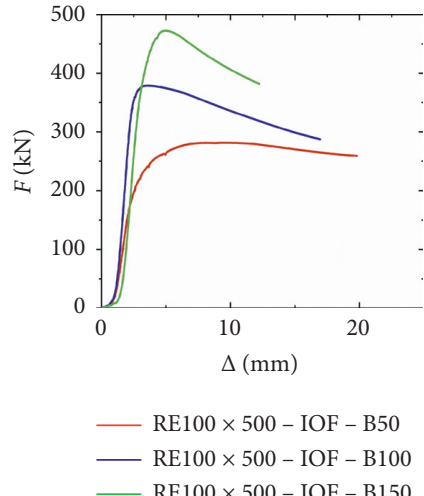

(c)

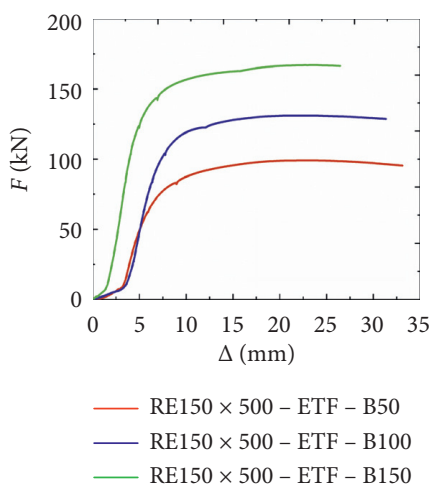

(f)

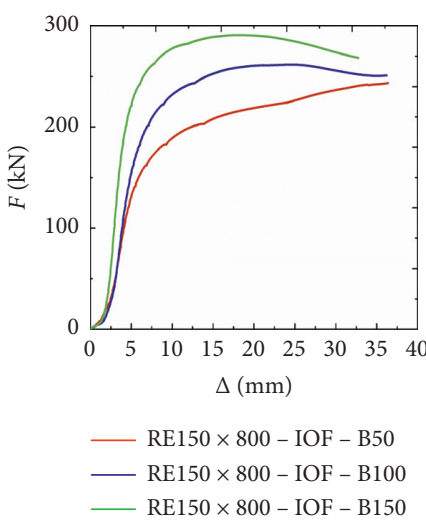

(i) 


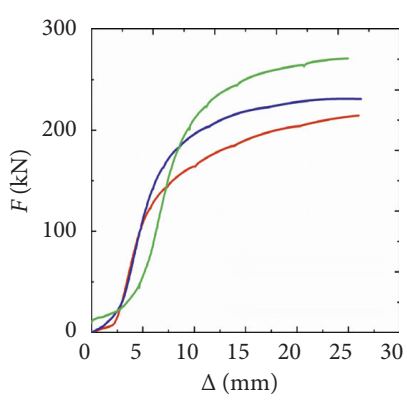

- RE150 $\times 800-$ ITF - B50

- RE150 $\times 800-$ ITF - B100

- RE150 $\times 800-$ ITF - B150

(j)

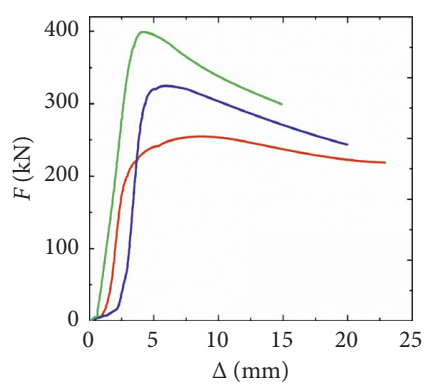

$$
\begin{aligned}
& \text { RE200 } \times 800-\text { IOF }- \text { B50 } \\
& \text { RE200 } \times 800-\text { IOF }- \text { B } 100 \\
& \text { RE200 } \times 800-\text { IOF }- \text { B } 150
\end{aligned}
$$

(k)

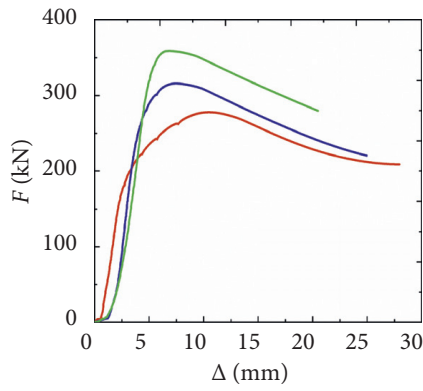

RE200 $\times 800-$ ITF - B50

- RE200 $\times 800-$ ITF - B100

- RE200 × $800-$ ITF - B150

(1)

FIGURE 6: Load-displacement curves of specimens with different bearing plate width. (a) RE100 $\times 500-$ EOF. (b) RE100 $\times 500-$ ETF. (c) RE100 $\times 800$ - IOF. (d) RE100 $\times 800$ - ITF. (e) RE150 $\times 500$ - EOF. (f) RE150 $\times 500-$ ETF. (g) RE200 $\times 500-$ EOF. (h) RE200 $\times 500-$ ETF. (i) RE150 × 800 - IOF. (j) RE150 ×800 - ITF. (k) RE $200 \times 800-$ IOF. (l) RE $200 \times 800-$ ITF.

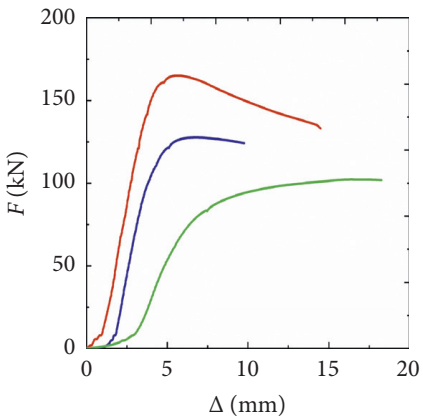

RE100 $\times 500-\mathrm{EOF}-\mathrm{B} 50$

RE150 $\times 500-\mathrm{EOF}-\mathrm{B} 50$

RE200 $\times 500-$ EOF - B50

(a)

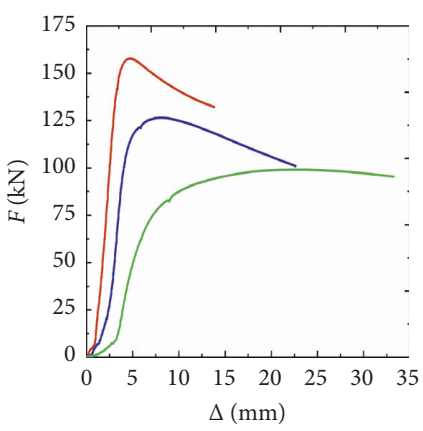

RE100 $\times 500-\mathrm{ETF}-\mathrm{B} 50$

- RE150 $\times 500-\mathrm{ETF}-\mathrm{B} 50$

RE200 $\times 500-\mathrm{ETF}-\mathrm{B} 50$

(d)

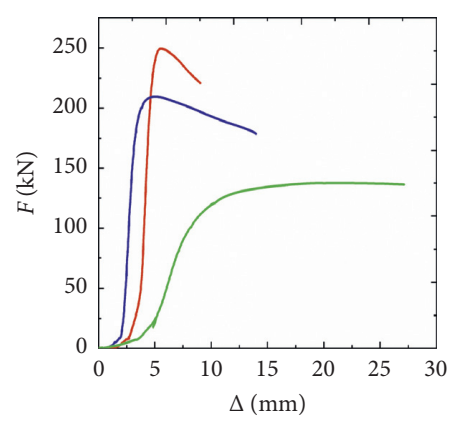

RE100 $\times 500-\mathrm{EOF}-\mathrm{B} 100$

RE150 $\times 500-\mathrm{EOF}-\mathrm{B} 100$

RE200 $\times 500-\mathrm{EOF}-\mathrm{B} 100$

(b)

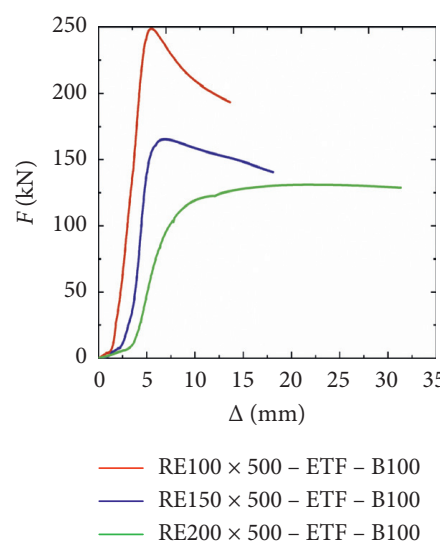

(e)

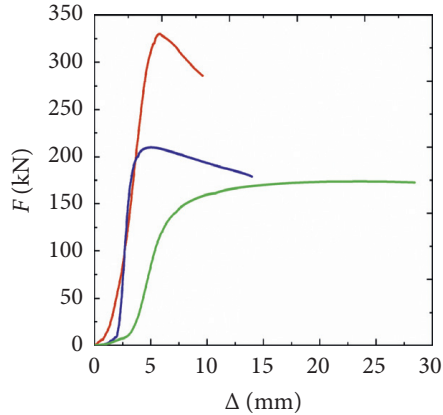

- RE100 $\times 500-\mathrm{EOF}-\mathrm{B} 150$

RE150 $\times 500-\mathrm{EOF}-\mathrm{B} 150$

RE200 $\times 500-$ EOF - B150

(c)

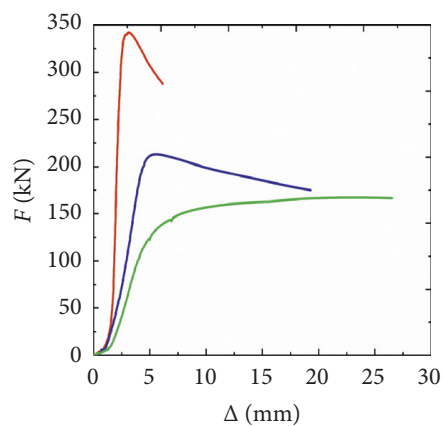

RE100 × $500-\mathrm{ETF}-\mathrm{B} 150$

$\mathrm{RE} 150 \times 500-\mathrm{ETF}-\mathrm{B} 150$

RE200 $\times 500-$ ETF - B150

(f)

Figure 7: Continued. 


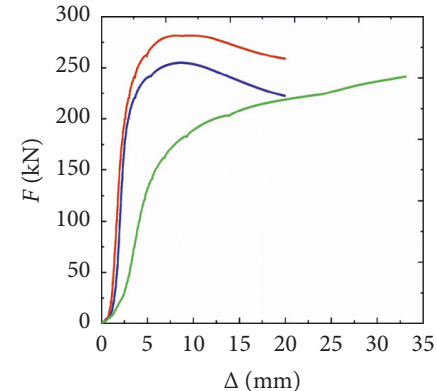

- RE100 $\times 800-$ IOF - B50

- RE150 $\times 800-$ IOF - B50

RE200 $\times 800-$ IOF - B50

(g)

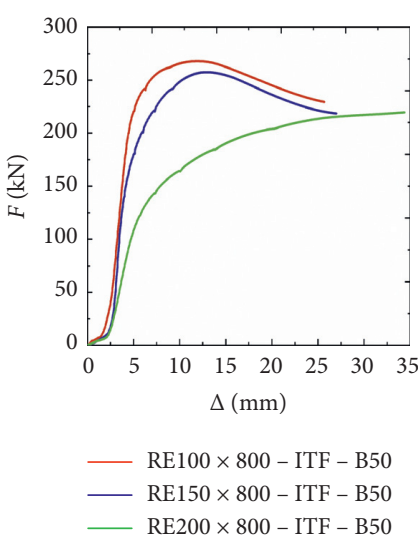

$(\mathrm{j})$

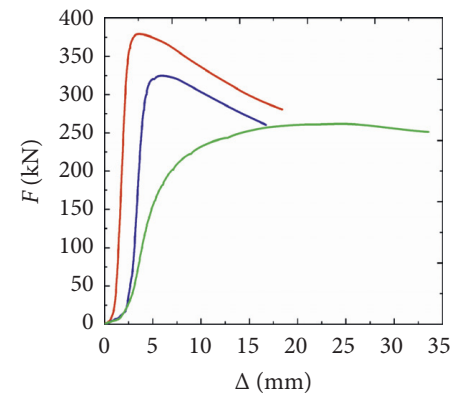

RE100 $\times 800-$ IOF - B100

- RE150 $\times 800-$ IOF - B100

- RE200 $\times 800-$ IOF - B100

(h)

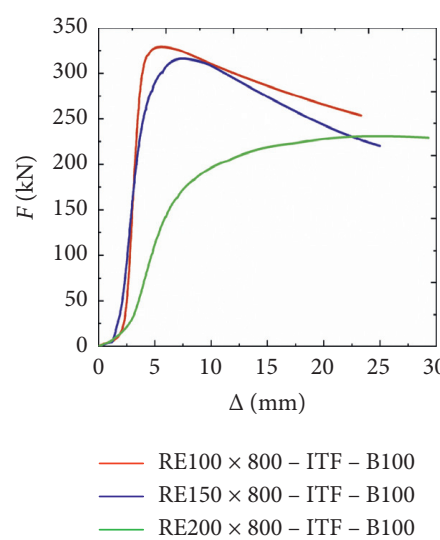

(k)

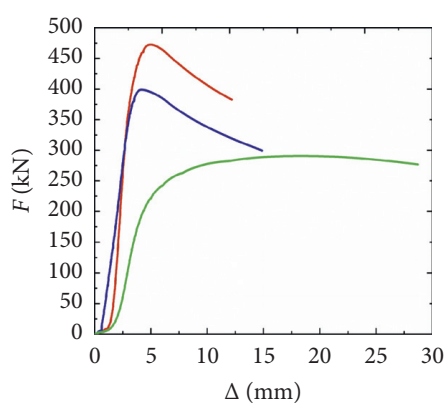

- RE100 $\times 800-$ IOF - B150

- RE150 $\times 800-$ IOF - B150

- RE200 $\times 800-$ IOF - B150

(i)

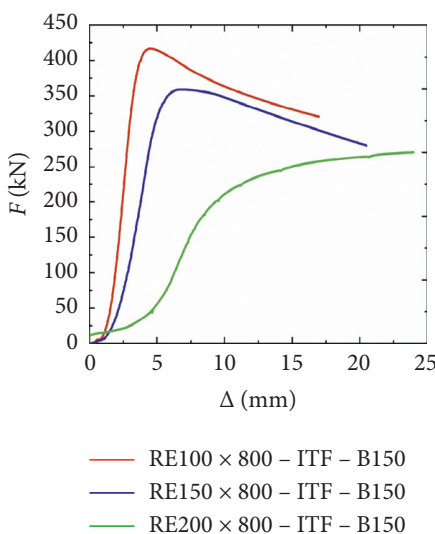

(l)

FIGURE 7: Load-displacement curves of specimens with different section length-width ratios. (a) EOF. (b) EOF. (c) EOF. (d) ETF. (e) ETF. (f) ETF. (g) IOF. (h) IOF. (i) IOF. (j) ITF. (k) ITF. (l) ITF.

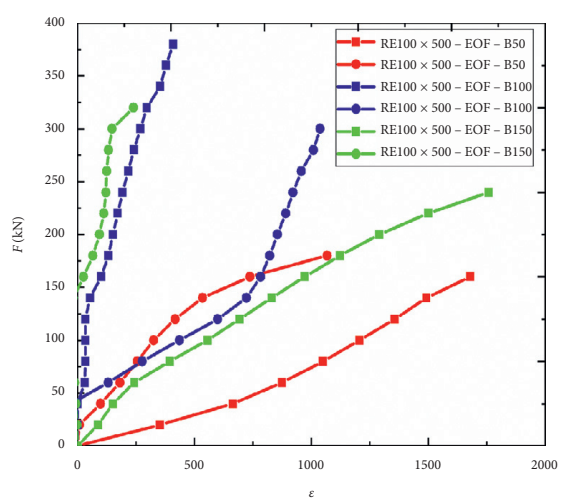

(a)

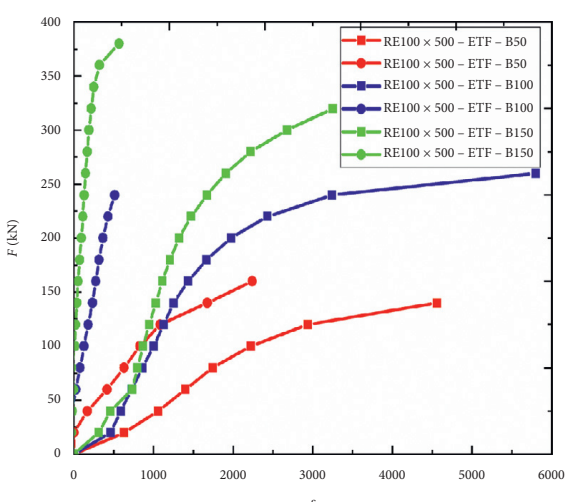

(b)

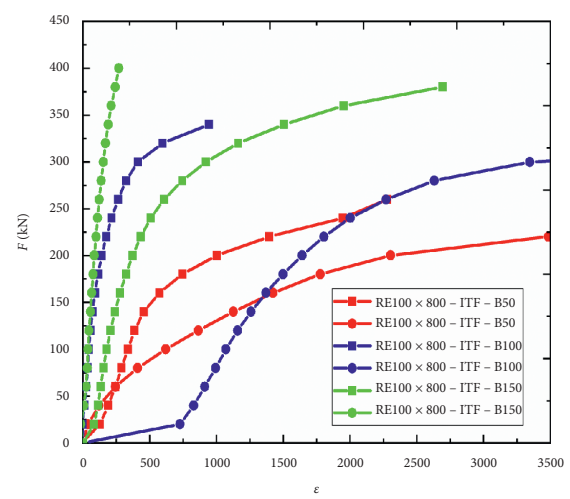

(c)

Figure 8: Continued. 


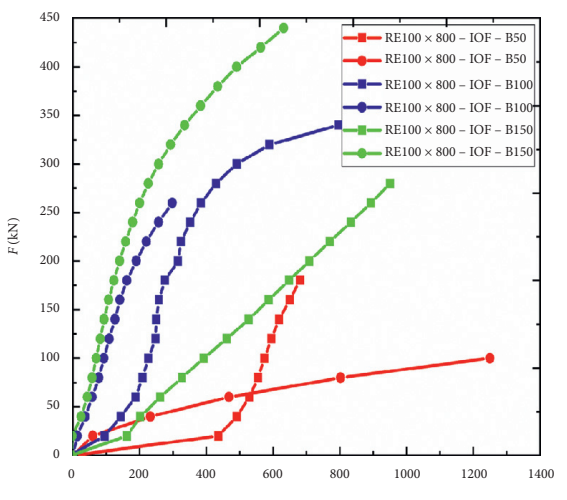

(d)

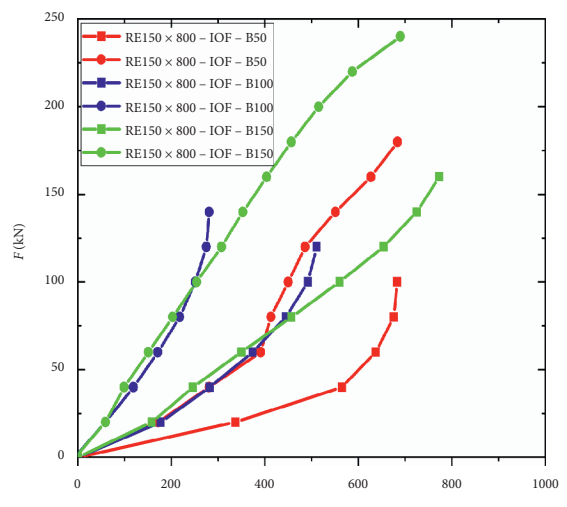

(g)

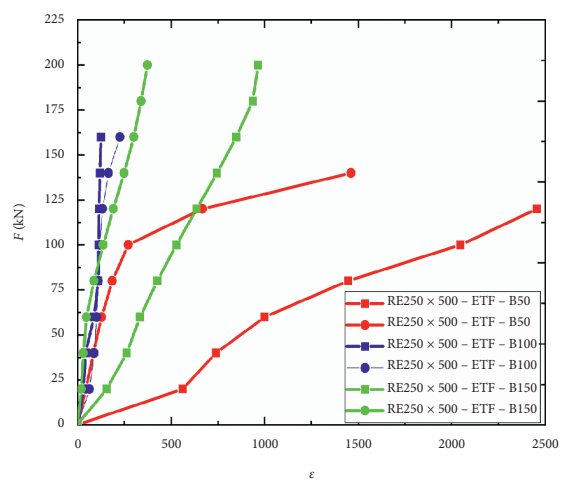

(j)

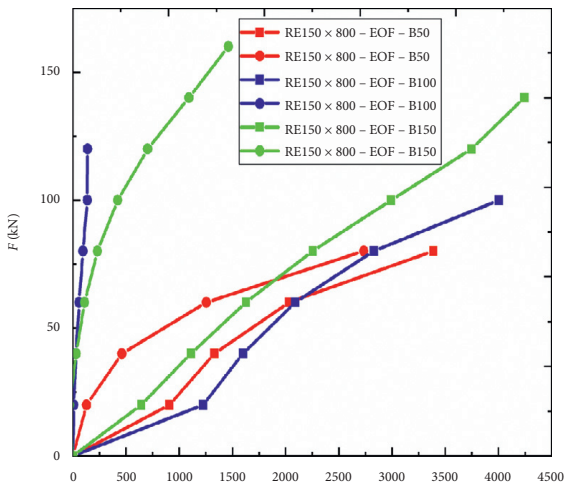

(e)

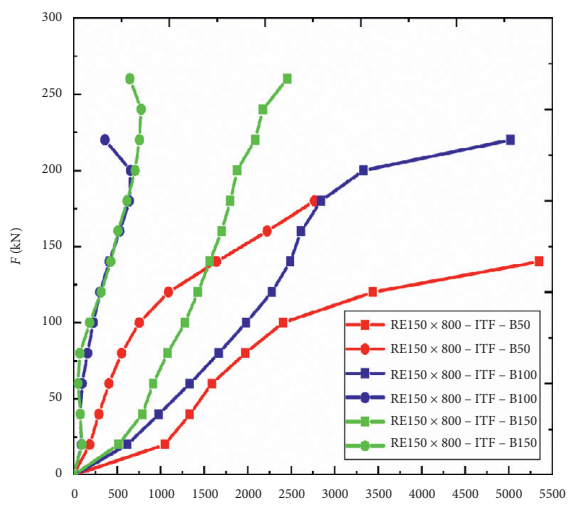

(h)

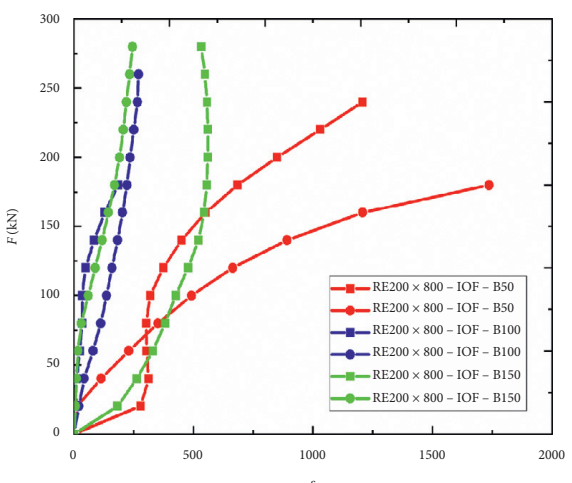

(k)

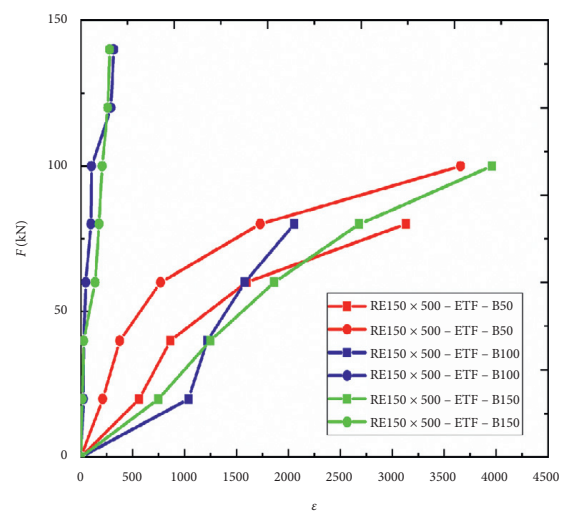

(f)

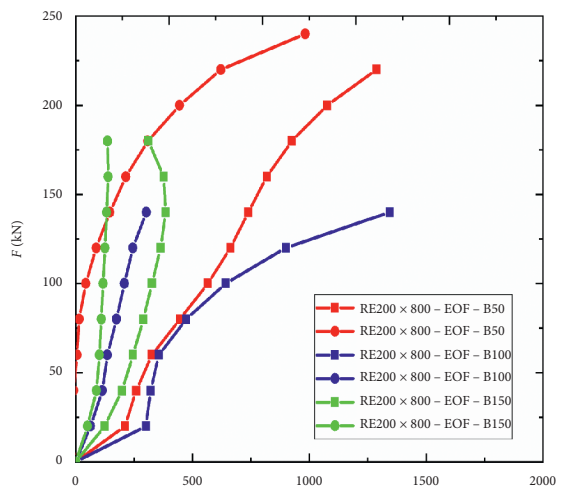

(i)

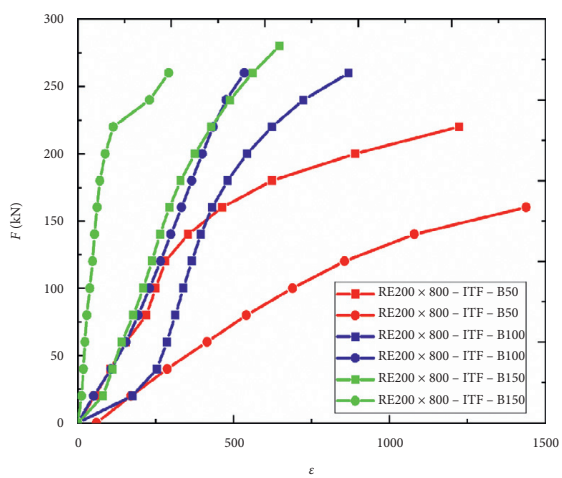

(1)

FIGURE 8: Load-strain curves of specimens with different bearing plate width. (a) RE100 $\times 500-$ EOF. (b) RE100 $\times 500-$ ETF. (c) RE100 $\times 800$ - ITF. (d) RE100 $\times 800$ - IOF. (e) RE150 ×500 - EOF. (f) RE150 ×500 - ETF. (g) RE150 × $800-$ IOF. (h) RE150 × $800-$ ITF. (i) RE200 $\times 500-$ EOF. (j) RE200 $\times 500-$ ETF. (k) RE200 $\times 800-$ IOF. (l) RE200 $\times 800-$ ITF.

[41] has carried out a lot of finite element parameter analyses on the web buckling performance of cold-formed channel steel under the action of bending moment and concentrated load to obtain a high precision formula for calculating the web buckling strength of cold-formed channel steel. Cevik [42] used the programming method to establish the web buckling strength calculation formulas of various coldformed components under various working conditions and compared with the test results and the current strength calculation standard formula to verify its accuracy. Young and Ellobody [43] carried out experimental research on three cold-curved thin-wall equilateral rolled triangular section columns with different lengths and different thicknesses fixed at both ends. By comparing the test results with the results simulated by ABAQUS finite element software, they found that the finite element software could accurately simulate the forces on the components.

In this paper, ABAQUS was used to simulate the web crippling performance of HSCF rectangular tubes under concentrated load under the influence of boundary 


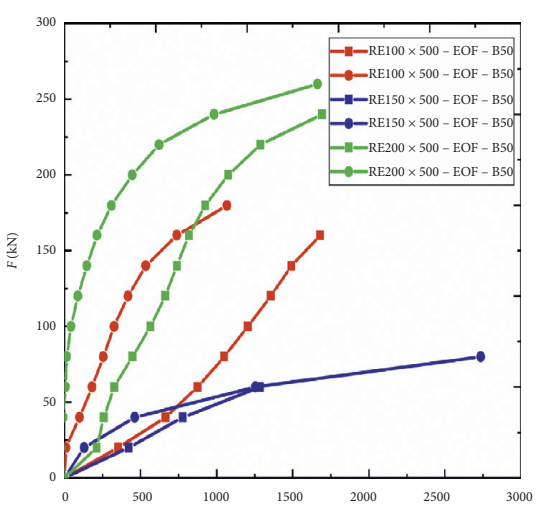

(a)

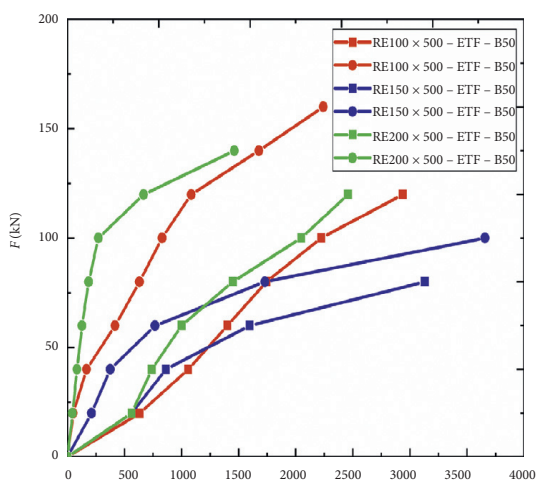

(d)

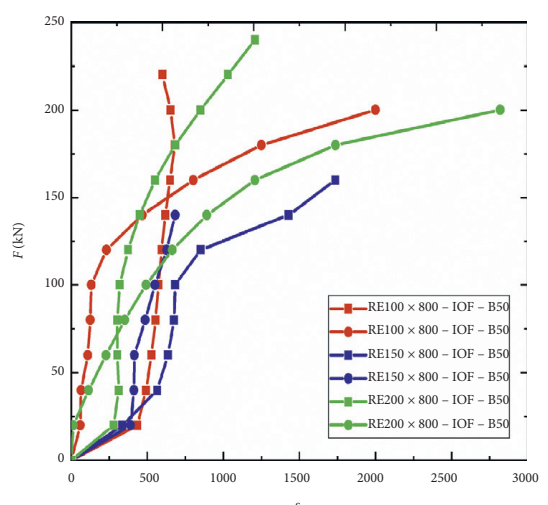

(g)

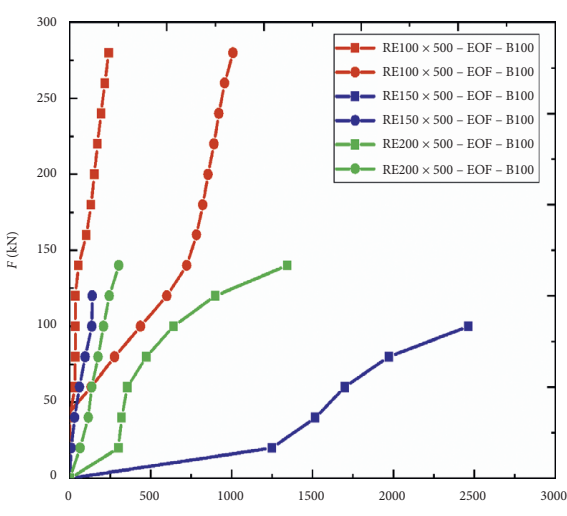

(b)

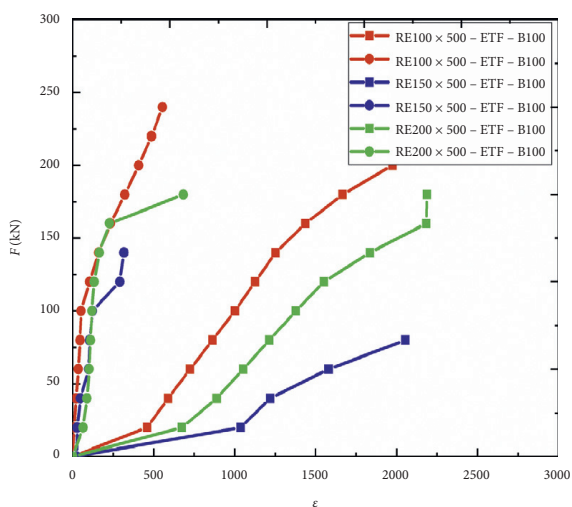

(e)

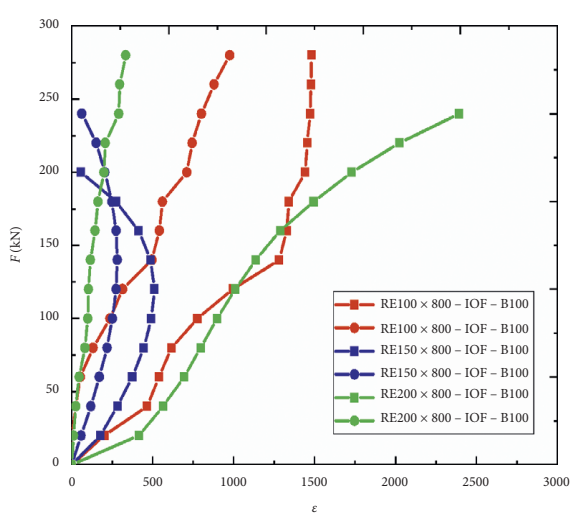

(h)

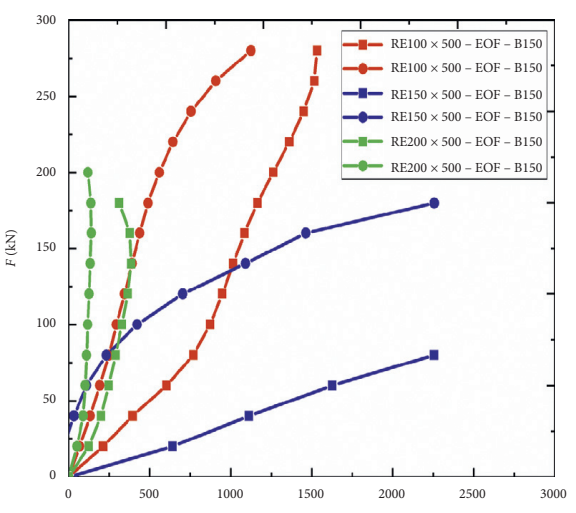

(c)

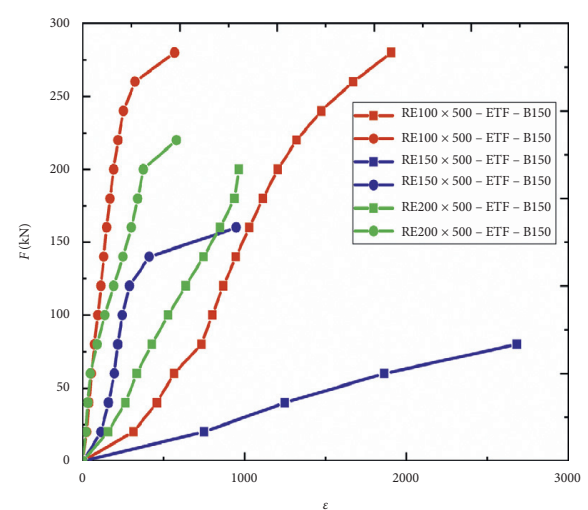

(f)

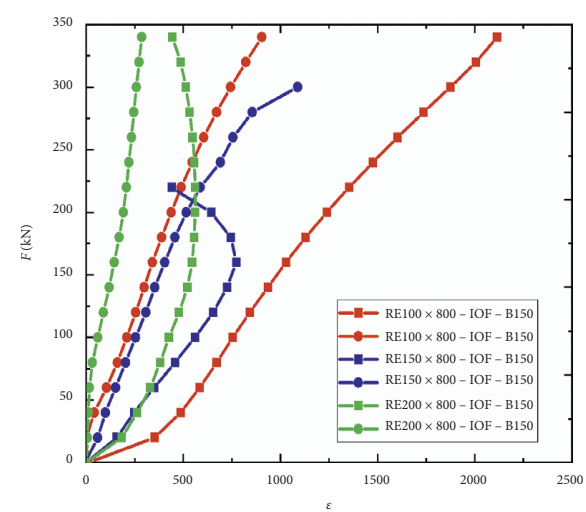

(i)

Figure 9: Continued. 


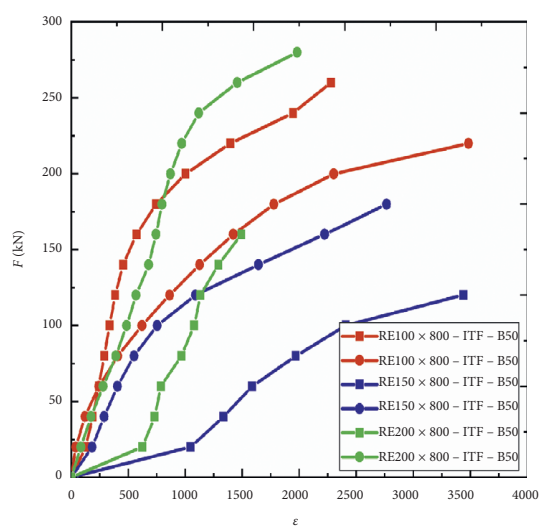

(j)

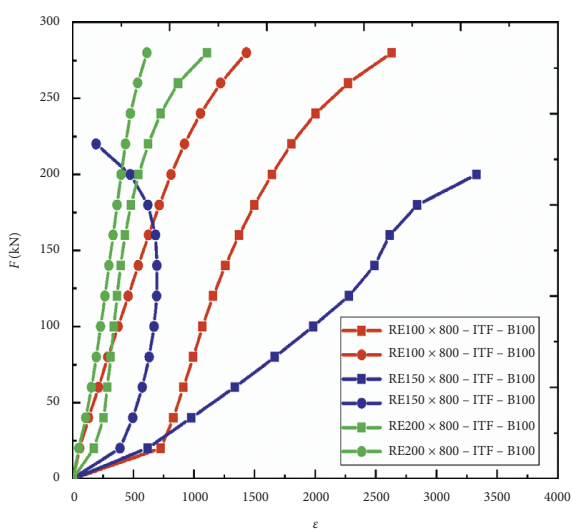

(k)

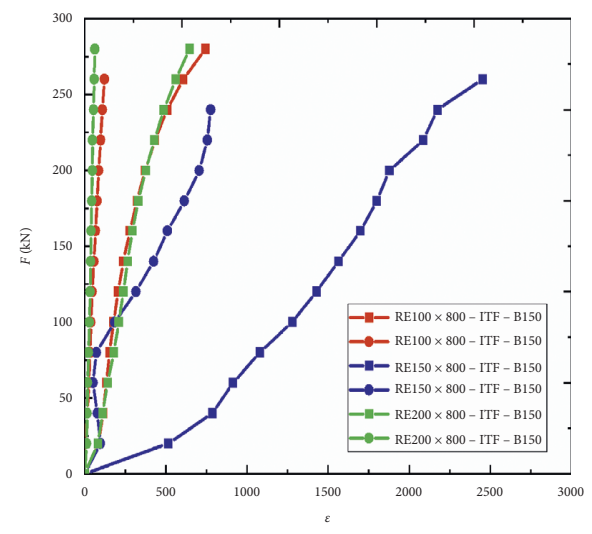

(l)

FIGURE 9: Load-strain curves of specimens with different section length-width ratios. (a) EOF. (b) EOF. (c) EOF. (d) ETF. (e) ETF. (f) ETF. (g) IOF. (h) IOF. (i) IOF. (j) ITF. (k) ITF. (l) ITF.

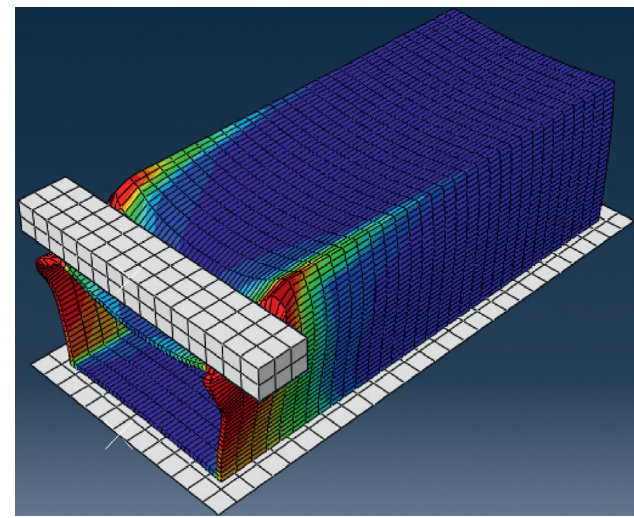

(a)

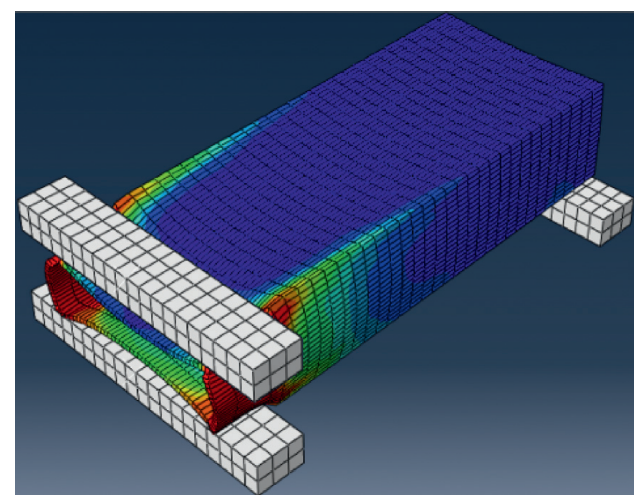

(c)

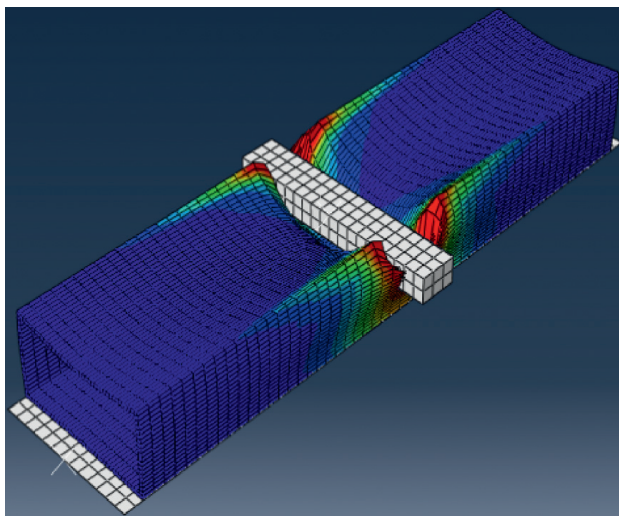

(b)

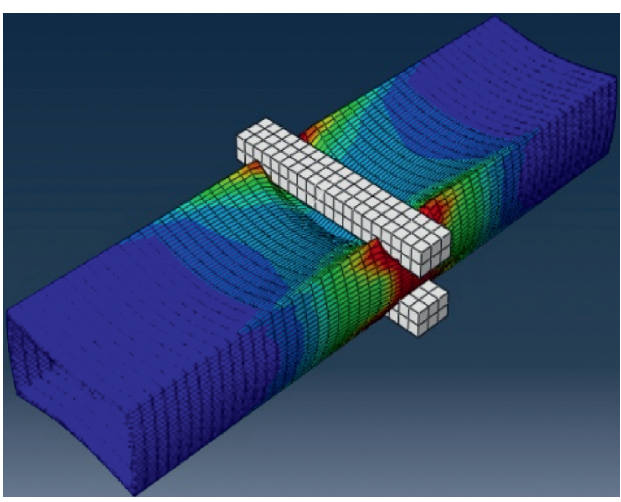

(d)

FIGURE 10: FE Failure modes of high strength cold-formed rectangular tubes under web crippling. (a) EOF. (b) IOF. (c) ETF. (d) ITF.

conditions and loading mode. In the numerical model, the boundary conditions of HSCF rectangular tube under the concentrated load consisted of EOF, ETF, IOF, and ITF, which were consistent with test scenarios. During the simulation, the surface load was applied to the bearing plate. The yield strength, ultimate tensile strength, and elastic modulus of the material were obtained via measured values in the tests. In addition, the eight-node solid element with reduced integration (C3D8R) was used to simulate high strength cold-formed rectangular tube and the bearing plates.

The residual stress of cold-formed thin-walled steel members is closely related to the production process. Rolling and bending are the two most common cold bending methods. The residual stress mainly consists of bending stress and membrane stress. The film stress is the most common in the rolled member, which is generally distributed in the corner of the member, so the residual stress at the 
TABLE 3: Ultimate capacities validation of finite element models.

\begin{tabular}{|c|c|c|c|c|c|}
\hline Specimen & $P_{\mathrm{cr}}(\mathrm{kN})$ & $P_{\text {FEA }}(\mathrm{kN})$ & Error (\%) & $P_{\text {crRE }}(\mathrm{kN})$ & $P_{\mathrm{crRE}} / P_{\mathrm{cr}}$ \\
\hline $\mathrm{RE} 100 \times 500-\mathrm{EOF}-\mathrm{B} 50$ & 165.1 & 166.3 & 0.73 & 165.2 & 1.00 \\
\hline $\mathrm{RE} 100 \times 500-\mathrm{EOF}-\mathrm{B} 100$ & 249.4 & 250.8 & 0.56 & 247.7 & 0.99 \\
\hline $\mathrm{RE} 100 \times 500-\mathrm{EOF}-\mathrm{B} 150$ & 330.0 & 331.5 & 0.45 & 330.2 & 1.00 \\
\hline $\mathrm{RE} 150 \times 500-\mathrm{EOF}-\mathrm{B} 50$ & 102.2 & 103.1 & 0.88 & 112.6 & 1.10 \\
\hline $\mathrm{RE} 150 \times 500-\mathrm{EOF}-\mathrm{B} 100$ & 137.5 & 139.8 & 1.70 & 142.5 & 1.04 \\
\hline $\mathrm{RE} 150 \times 500-\mathrm{EOF}-\mathrm{B} 150$ & 173.8 & 176.6 & 1.60 & 172.3 & 0.99 \\
\hline $\mathrm{RE} 200 \times 500-\mathrm{EOF}-\mathrm{B} 50$ & 127.8 & 128.9 & 0.86 & 124.7 & 0.98 \\
\hline $\mathrm{RE} 200 \times 500-\mathrm{EOF}-\mathrm{B} 100$ & 152.8 & 155.4 & 1.70 & 166.7 & 1.09 \\
\hline $\mathrm{RE} 200 \times 500-\mathrm{EOF}-\mathrm{B} 150$ & 209.8 & 215.3 & 2.60 & 208.7 & 0.99 \\
\hline $\mathrm{RE} 100 \times 800-\mathrm{IOF}-\mathrm{B} 50$ & 254.9 & 255.6 & 0.27 & 257.0 & 1.01 \\
\hline $\mathrm{RE} 100 \times 800-\mathrm{IOF}-\mathrm{B} 100$ & 324.7 & 326.1 & 0.43 & 326.0 & 1.00 \\
\hline $\mathrm{RE} 100 \times 800-\mathrm{IOF}-\mathrm{B} 150$ & 399.0 & 400.5 & 0.38 & 395.0 & 0.99 \\
\hline $\mathrm{RE} 150 \times 800-\mathrm{IOF}-\mathrm{B} 50$ & 281.6 & 283.1 & 0.55 & 283.0 & 1.00 \\
\hline $\mathrm{RE} 150 \times 800-\mathrm{IOF}-\mathrm{B} 100$ & 379.0 & 380.7 & 0.44 & 378.0 & 1.00 \\
\hline $\mathrm{RE} 150 \times 800-\mathrm{IOF}-\mathrm{B} 150$ & 472.4 & 476.3 & 0.82 & 473.0 & 1.00 \\
\hline RE200 × $800-$ IOF - B50 & 243.7 & 250.1 & 2.64 & 225.0 & 0.92 \\
\hline RE200 $\times 800-$ IOF - B100 & 261.8 & 267.3 & 2.11 & 262.0 & 1.00 \\
\hline RE $200 \times 800-$ IOF - B 150 & 291.0 & 296.8 & 2.01 & 299.0 & 1.03 \\
\hline $\mathrm{RE} 100 \times 500-\mathrm{ETF}-\mathrm{B} 50$ & 157.8 & 158.6 & 0.51 & 160.1 & 1.01 \\
\hline $\mathrm{RE} 100 \times 500-\mathrm{ETF}-\mathrm{B} 100$ & 248.8 & 250.7 & 0.76 & 248.6 & 1.00 \\
\hline $\mathrm{RE} 100 \times 500-\mathrm{ETF}-\mathrm{B} 150$ & 342.0 & 343.4 & 0.41 & 337.1 & 0.99 \\
\hline $\mathrm{RE} 150 \times 500-\mathrm{ETF}-\mathrm{B} 50$ & 99.0 & 99.2 & $0.20^{\min }$ & 101.9 & 1.03 \\
\hline $\mathrm{RE} 150 \times 500-\mathrm{ETF}-\mathrm{B} 100$ & 131.2 & 133.1 & 1.45 & 132.1 & 1.01 \\
\hline $\mathrm{RE} 150 \times 500-\mathrm{ETF}-\mathrm{B} 150$ & 167.0 & 169.6 & 1.56 & 162.4 & 0.97 \\
\hline $\mathrm{RE} 200 \times 500-\mathrm{ETF}-\mathrm{B} 50$ & 129.3 & 131.8 & 1.93 & 118.1 & $0.91^{\mathrm{min}}$ \\
\hline $\mathrm{RE} 200 \times 500-\mathrm{ETF}-\mathrm{B} 100$ & 165.3 & 168.5 & 1.94 & 164.6 & 1.00 \\
\hline $\mathrm{RE} 200 \times 500-\mathrm{ETF}-\mathrm{B} 150$ & 213.2 & 220.1 & $3.24^{\max }$ & 211.1 & 0.99 \\
\hline RE100 × 800 - ITF - B50 & 267.9 & 268.7 & 0.30 & 274.0 & 1.02 \\
\hline $\mathrm{RE} 100 \times 800-\mathrm{ITF}-\mathrm{B} 100$ & 329.0 & 332.9 & 1.19 & 338.0 & 1.03 \\
\hline RE100 × $800-$ ITF - B150 & 417.0 & 422.4 & 1.29 & 402.0 & 0.96 \\
\hline $\mathrm{RE} 150 \times 800-\mathrm{ITF}-\mathrm{B} 50$ & 230.6 & 231.1 & 0.22 & 230.1 & 1.00 \\
\hline $\mathrm{RE} 150 \times 800-\mathrm{ITF}-\mathrm{B} 100$ & 231.1 & 233.8 & 1.17 & 257.0 & 1.11 \\
\hline $\mathrm{RE} 150 \times 800-\mathrm{ITF}-\mathrm{B} 150$ & 270.9 & 274.7 & 1.40 & 270.4 & 1.00 \\
\hline RE200 × $800-$ ITF - B50 & 278.0 & 280.2 & 0.79 & 259.5 & 0.93 \\
\hline RE200 $\times 800-$ ITF - B100 & 232.5 & 235.9 & 1.46 & 309.0 & $1.33^{\max }$ \\
\hline RE $200 \times 800-$ ITF - B 150 & 359.0 & 366.5 & 2.09 & 358.5 & 1.00 \\
\hline
\end{tabular}

corner is large. Moen et al. [44] conducted a finite element analysis of the residual stress distribution of the bending members and found that the membrane stress in the members could be ignored. The bending stress is mainly determined by the processing technology of cold-formed thin-walled steel members, which is not considered here.

Then, to verify the accuracy of the proposed numerical model of HSCF rectangular tubes under web crippling, we analyzed thirty-six high strength cold-formed rectangular steel tubes with web failure and compared the finite element results to experimental values. The simulation results of failure modes and ultimate bearing capacity of HSCF rectangular steel tubes subjected to web crippling were also compared with the test results. The experimental results of failure modes (as shown in Figure 5) of HSCF rectangular tubes under web crippling were compared with the numerical prediction results, as illustrated in Figure 10. It can be seen that the failure mode predicted by the numerical method is in good agreement with the experimental results. Moreover, the comparison of the ultimate bearing capacity between the tests and numerical analyses is presented in
Table 3. The test results conform to the numerical analyses with the maximum error of $3.24 \%$ and the minimum error of $0.20 \%$. Overall, the results demonstrate that the test results are in good agreement with the numerical simulation in the web crippling strength and failure mode. In order to better verify the correctness of the finite element model, specimens $(\mathrm{RE} 100 \times 500-\mathrm{EOF}-\mathrm{B} 50, \quad \mathrm{RE} 100 \times 500-\mathrm{ETF}-\mathrm{B} 50$, $\mathrm{RE} 100 \times 800-\mathrm{IOF}-\mathrm{B} 50$, and RE100 $\times 800-\mathrm{ITF}-\mathrm{B} 50$ ) were selected to draw the load-displacement curve. Figures 11 and 12 show the load-displacement curves obtained by experiment and finite element simulation, respectively. It is found that the load-displacement curves obtained by experiment and the finite element method are in good agreement.

\section{Design Formulas}

Based on material strength failure of HSCF rectangular steel tubes under local compression, the calculated value of the Chinese steel structures design code is much higher than the test value. On the other hand, the influence of the bearing 


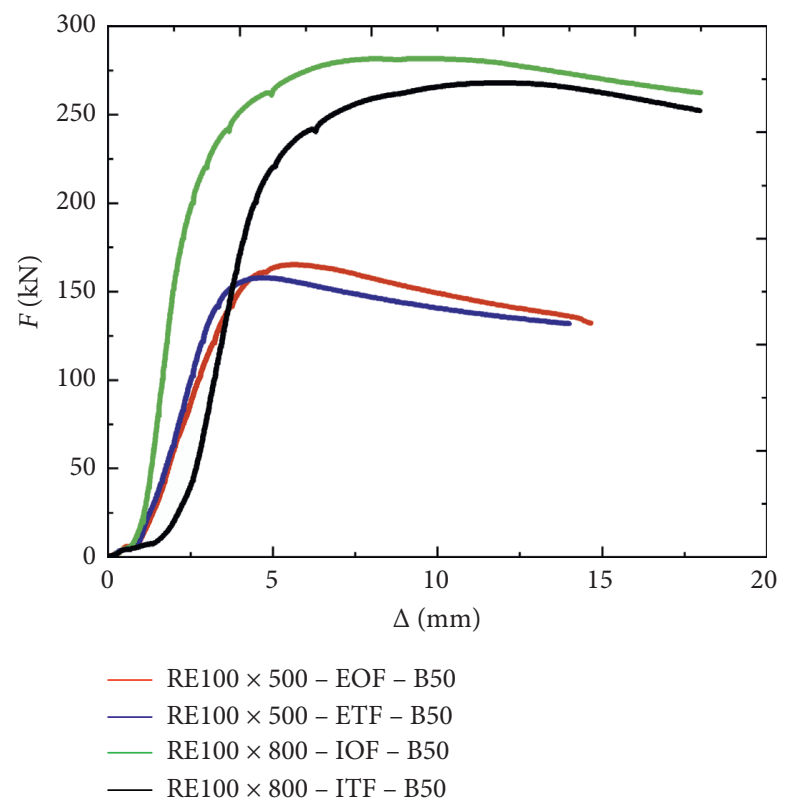

Figure 11: Load-displacement curves obtained by experiment.

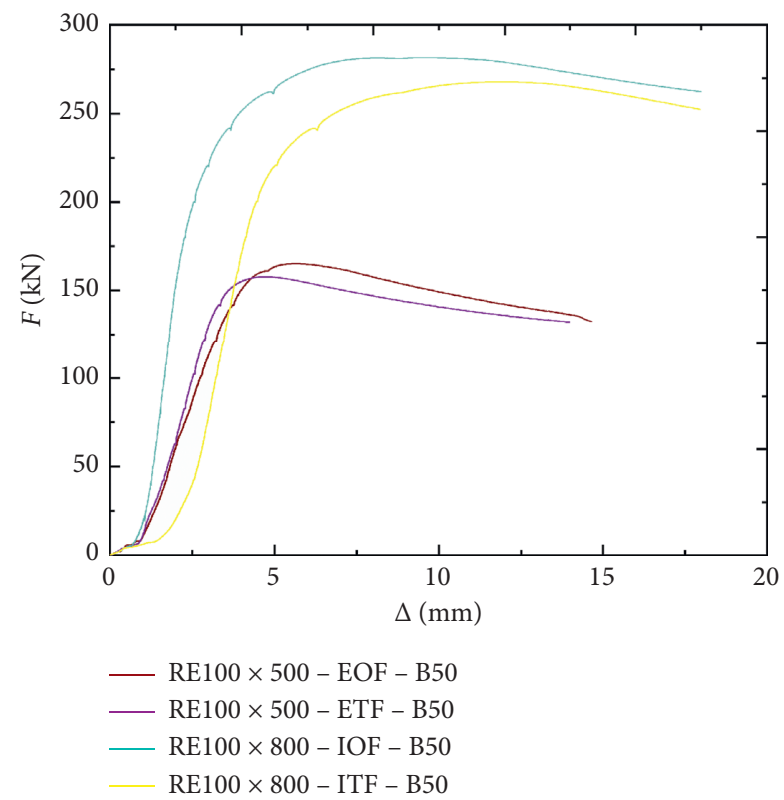

FIGURE 12: Load-displacement curves obtained by finite element simulation.

plate width on web crippling strength is ignored in the European steel structures design code, which tends to be conservative. Regarding that the calculation of ultimate bearing capacity in European steel structures design code is complicated and conservative, we developed new calculation equations (1)-(4) of web ultimate bearing capacity for HSCF rectangular steel tubes in this paper by considering the influence of the bearing plate width. The calculation results conform to the experimental values well. The average values of the ratios of calculated values and test values for the four formulas of boundary and loading modes are 0.91, 0.99, 0.99, and 1.04, respectively. The coefficients of variation are 0.083 ,
$0.068,0.059$, and 0.352 , respectively. The comparison results are given in Table 3.

$$
P_{\mathrm{EOF}}=82.7+7.64 \cdot a+0.000259 \cdot a \cdot h^{2}-0.0858 \cdot h \cdot a,
$$

$$
P_{\mathrm{IOF}}=188-4.7 \cdot a-0.000336 \cdot a \cdot h^{2}+0.0944 \cdot h \cdot a,
$$

$$
P_{\mathrm{ETF}}=71.6+8.57 \cdot a+0.000298 \cdot a \cdot h^{2}-0.0978 \cdot h \cdot a \text {, }
$$




$$
P_{\mathrm{ITF}}=210+7.43 \cdot a+0.000293 \cdot a \cdot h^{2}-0.0908 \cdot h \cdot a,
$$

where $P_{\mathrm{EOF}}$ is web crippling ultimate capacity under EOF condition; $P_{\mathrm{IOF}}$ is web crippling ultimate capacity under IOF condition; $P_{\text {ETF }}$ is web crippling ultimate capacity under ETF condition; $P_{\text {ITF }}$ is web crippling ultimate capacity under ITF condition; $h$ is the height of specimens; and $a$ is bearing plate width.

\section{Conclusions}

In this paper, the experimental and numerical investigations are conducted on high strength cold-formed (HSCF) rectangular steel tubes under concentrated loading at web positions along the transverse direction. Some conclusions can be drawn as follows:

(1) The ultimate capacity of HSCF rectangular steel tubes under web crippling increases with larger bearing plate width and width-to-height ratio

(2) The HSCF rectangular steel tube subjected to interior bearing load has higher ultimate strength and deformation capacity than the counterpart that is subjected to end bearing load

(3) Under the same width of bearing plates, the ultimate bearing capacity and deformation capacity of HSCF rectangular steel tubes do not change significantly under four loading conditions

(4) Finite element model is established, and the comparison between it and experimental results demonstrates that the proposed numerical model can accurately predict the behavior of HSCF rectangular steel tubes under web crippling

(5) The calculation equations of web ultimate bearing capacity for HSCF rectangular steel tubes are developed in this paper, and they can predict the experimental values well

Recent literature has reported the efficiency of the piezoelectric transducers enabled the structural health monitoring method $[45,46]$ and the percussion-based method [47] in detecting structural damages; we will apply these approaches to identify the damages in the high strength cold-formed rectangular steel tubes in the future.

\section{Nomenclature}

EOF: End-one-flange

IOF: Interior-one-flange

ETF: End-two-flange

ITF: Interior-two-flange

$b / h: \quad$ Width-to-height ratio

$P_{c r}: \quad$ Experimental web crippling ultimate capacity

$P_{\text {ETF }}$ : Web crippling ultimate capacity under ETF condition

$P_{\text {EOF }}$ : Web crippling ultimate capacity under EOF condition

$P_{\text {IOF }}:$ Web crippling ultimate capacity under IOF condition
$P_{\text {crRE }}$ : Web crippling ultimate capacity obtained by using formulas the paper put forward

$\sigma_{y}: \quad$ Tensile yield stress

$\sigma_{u}: \quad$ Ultimate tensile stress

$\varepsilon_{f}$ : Elongation after fracture

E: $\quad$ Elastic modulus

$b$ : Width of section

$h$ : Height of section

$L: \quad$ Length of specimens

$a$ : Width of bearing plates

$t$ : Wall thickness of specimens

$P_{\text {ITF }}$ : Web crippling ultimate capacity under ITF condition.

\section{Data Availability}

The data are real and reliable in this paper, including original experimental data and software analysis data. The data used to support the findings of this study are available from the corresponding author upon request.

\section{Conflicts of Interest}

The authors declare no conflicts of interest.

\section{Acknowledgments}

This research work was supported by the National Natural Science Foundation of China (no. 51778065). The authors expressed their gratitude to Xinfeng Steel Processing Plant for the processing of test specimens. The tests were conducted in Laboratory on Structural Engineering and Disaster Reduction at Yangtze University. The support provided by the laboratory staff is gratefully acknowledged.

\section{References}

[1] R. P. Rokade, K. Balaji Rao, and B. Palani, "Determination of modelling error statistics for cold-formed steel columns," Advances in Civil Engineering, vol. 2020, Article ID 3740510, 25 pages, 2020.

[2] J. Jiang, Z. J. Ye, W. Bao, X. Wang, Y. B. Wang, and X. H. Dai, "Flexural buckling behaviour of $690 \mathrm{MPa}$ high strength steel H-section columns," Engineering Structures, vol. 200, p. 109718, 2019.

[3] J. Jiang, W. Bao, Z. Y. Peng, and Y. B. Wang, X. H. Dai, Experimental investigation on mechanical behaviours of TMCP high strength steel," Construction and Building Materials, vol. 200, pp. 664-680, 2019.

[4] J. Jiang, W. Bao, Z. Y. Peng, and X. H. Dai, "Creep property of TMCP high-strength steel Q690CFD at elevated temperatur," Journal of Materials in Civil Engineering, vol. 32, no. 2, 2020.

[5] G. Du, M. Babic, F. Wu, X. Zeng, and X.-M. Bie, "Experimental and numerical studies on concrete filled circular steel tubular (CFCST) members under impact loads," International Journal of Civil Engineering, vol. 17, no. 8, pp. 1211-1226, 2019.

[6] G. Du, J. Zhang, Y. Li, J. Zhang, and L. Zeng, "Experimental study on hysteretic model for L-shaped concrete-filled steel tubular column subjected to cyclic loading," Thin-Walled Structures, vol. 144, p. 106278, 2019. 
[7] Y. Dong, Z. Feng, H. Hu, J. He, Q. Zhang, and F. Wang, "The horizontal bearing capacity of composite concrete-filled steel tube piles," Advances in Civil Engineering, vol. 2020, Article ID 3241602, 15 pages, 2020.

[8] T. Cadenazzi, M. Rossini, S. Nolan, G. Dotelli, A. Arrigoni, and A. J. Nanni, "Resilience and economical sustainability of a FRP reinforced concrete bridge in Florida: LCC analysis at the design stage," in Proceedings of 6th International Symposium on Life-Cycle Civil Engineering IALCCE 2018, pp. 2913-2920, CRC Press/Balkema, Ghent, Belgium, October 2019.

[9] B. Di, J. Wang, H. Li, J. Zheng, Y. Zheng, and G. Song, "Investigation of bonding behavior of FRP and steel bars in self-compacting concrete structures using acoustic emission method," Sensors, vol. 19, no. 1, p. 159, 2019.

[10] L. Zhou, Y. Zheng, G. Song, D. Chen, and Y. Ye, "Identification of the structural damage mechanism of BFRP bars reinforced concrete beams using smart transducers based on time reversal method," Construction and Building Materials, vol. 220, pp. 615-627, 2019.

[11] J. H. Ordoñez, R. R. Ambriz, C. García, G. Plascencia, and D. Jaramillo, "Overloading effect on the fatigue strength in resistance spot welding joints of a DP980 steel," International Journal of Fatigue, vol. 121, pp. 163-171, 2019.

[12] J. Peng, L. Xiao, J. Zhang, C. S. Cai, and L. Wang, "Flexural behavior of corroded HPS beams," Engineering Structures, vol. 195, pp. 274-287, 2019.

[13] L. Huo, C. Li, T. Jiang, and H.-N. Li, "Feasibility study of steel bar corrosion monitoring using a piezoceramic transducer enabled time reversal method," Applied Sciences, vol. 8, no. 11, p. 2304, 2018.

[14] W. Li, T. Liu, D. Zou, J. Wang, and T.-H. Yi, "PZT based smart corrosion coupon using electromechanical impedance," Mechanical Systems and Signal Processing, vol. 129, pp. 455469, 2019.

[15] T. Jiang, Y. Zhang, L. Wang, L. Zhang, and G. Song, "Monitoring fatigue damage of modular bridge expansion joints using piezoceramic transducers," Sensors, vol. 18, no. 11, p. 3973, 2018.

[16] G. A. Riveros, H. Mahmoud, and C. M. Lozano, "Fatigue repair of underwater navigation steel structures using carbon fiber reinforced polymer (CFRP)," Engineering Structures, vol. 173, pp. 718-728, 2018.

[17] N. Li, F. Wang, and G. Song, "New entropy-based vibroacoustic modulation method for metal fatigue crack detection: an exploratory study," Measurement, vol. 150, p. 107075, 2020.

[18] H. Tavakoli and M. M. Afrapoli, "Robustness analysis of steel structures with various lateral load resisting systems under the seismic progressive collapse," Engineering Failure Analysis, vol. 83, pp. 88-101, 2018.

[19] ASCE, Specification for the Design of Cold-Formed Stainless Steel Structural Members, American Society of Civil Engineers, Reston, VA, USA, 2002.

[20] AS/NZS 4673e2001, Cold-Formed Stainless Steel Structures, Standards Association of Australia, Sydney, Australia, 2001.

[21] NAS, North American Specification for the Design of ColdFormed Steel Structural Members, American Iron and Steel Institute, Washington, DC, USA, 2001.

[22] A. Uzzaman, J. B. P. Lim, D. Nash, J. Rhodes, and B. Young, "Cold-formed steel sections with web openings subjected to web crippling in two-flange loading conditions-part I: tests and finite element analysis," Thin-Walled Structures, vol. 56, pp. 38-48, 2012.

[23] A. Uzzaman, J. B. P. Lim, D. Nash, J. Rhodes, and B. Young, "Cold-formed steel sections with web openings subjected to web crippling under two-flange loading conditions-part II: parametric study and proposed design equations," ThinWalled Structures, vol. 56, pp. 79-87, 2012.

[24] M. Macdonald and M. A. Heiyantuduwa, "A design rule for web crippling of cold-formed steel lipped channel beams based on nonlinear FEA," Thin-Walled Structures, vol. 53, pp. 123-130, 2012.

[25] F. Zhou and B. Young, "Aluminum tubular sections subjected to web crippling-part I: tests and finite element analysis," Thin-Walled Structures, vol. 46, no. 4, pp. 339-351, 2008.

[26] F Zhou and B. Young, "Aluminum tubular sections subjected to web crippling-part II: proposed design equations," Thin Walled Structures, vol. 46, no. 4, pp. 352-361, 2008.

[27] F. Zhou and B. Young, "Web crippling of aluminium tubes with perforated webs," Engineering Structures, vol. 32, no. 5, pp. 1397-1410, 2010.

[28] Y. Chen, X. Chen, and C. Wang, "Aluminum tubular sections subjected to web crippling," Thin-Walled Structures, vol. 90, pp. 49-60, 2015.

[29] North American Specification (NAS), North American Specification for the Design of Cold-Formed Steel Structural Members. AISI S100-16, American Iron and Steel Institute (AISI), Washington, DC, USA, 2016.

[30] Standards Australia, Australian/New Zealand Standard (AS/ NZS). Cold-Formed Steel Structures. AS/NZS 4600, Standards Australia, Sydney, Australia, 2005.

[31] European Committee for Standardization (EC3), Eurocode 3: Design of Steel Structures-Part 1-3: General Rules-Supplementary Rules for Cold-Formed Members and Sheeting. EN 1993-1-3, European committee for standardization (CEN), Brussels, Belgium, 2006.

[32] Standards Australia, Australian Standard (AS). Steel Structures. AS 4100, Standards Australia, Sydney, Australia, 1998.

[33] H.-T. Li and B. Young, "Behaviour of cold-formed high strength steel RHS under localised bearing forces," Engineering Structures, vol. 183, pp. 1049-1058, 2019.

[34] H.-T. Li and B. Young, "Tests of cold-formedhighstrength steel tubular sections undergoing webcrippling," Engineering Structures, vol. 141, pp. 571-583, 2017.

[35] H.-T. Li and B. Young, "Design of cold-formed high strength steel tubular sections undergoing web crippling," Thin-Walled Structures, vol. 133, pp. 192-205, 2018.

[36] J.-L. Ma, T.-M. Chan, and B. Young, "Experimental investigation of cold-formed high strength steel tubular beams," Engineering Structures, vol. 126, pp. 200-209, 2016.

[37] B. Young and G. Hancock, "Web crippling tests of high strength cold-formed channels," Advances in Steel Structures (ICASS'99), vol. 1, pp. 357-366, 1999.

[38] F. Zhou and B. Young, "Cold-formed high-strength stainless steel tubular sections subjected to web crippling," Journal of Structural Engineering, vol. 133, no. 3, pp. 368-377, 2007.

[39] GB/T 228-2002, "Chinese code. Metallic materials-tensile testing at ambient temperature," Code of China, Beijing, China, GB/T 228-2002, 2002.

[40] S. H. Pham, C. H. Pham, and G. J. Hancock, "Shearing buckling of thin-walled channel sections with complex stiffened webs," Research Report No. R924, The University of Sydney, Sydney, Australia, 2012.

[41] W.-X. Ren, S.-E. Fang, and B. Young, "Analysis and design of cold-formed steel channels subjected to combined bending and web crippling," Thin-walled Structures, vol. 44, no. 3, pp. 314-320, 2006.

[42] A. Cevik, "A new formulation for web crippling strength of cold-formed steel sheeting using genetic programming," 
Journal of Constructional Steel Research, vol. 63, no. 7, pp. 867-883, 2007.

[43] B. Young and E. Ellobody, "Buckling analysis of cold-formed steel lipped angle columns," Journal of Structural Engineering, vol. 131, no. 10, pp. 1570-1579, 2005.

[44] C. D. Moen, T. Igusa, and B. W. Schafer, "Prediction of residual stresses and strains in cold-formed steel members," Thin-Walled Structures, vol. 46, no. 11, pp. 1274-1289, 2008.

[45] F. Wang and G. Song, "Bolt early looseness monitoring using modified vibro-acoustic modulation by time-reversal," $M e$ chanical Systems and Signal Processing, vol. 130, pp. 349-360, 2019.

[46] F. Wang, S. C. M. Ho, L. Huo, and G. Song, "A novel fractal contact-electromechanical impedance model for quantitative monitoring of bolted joint looseness," IEEE Access, vol. 6, pp. 40212-40220, 2018.

[47] F. Wang, S. C. M. Ho, and G. Song, "Modeling and analysis of an impact-acoustic method for bolt looseness identification," Mechanical Systems and Signal Processing, vol. 133, pp. 106249, 2019. 